Article

\title{
Improving Cooling Performance of Injection Molding Tool with Conformal Cooling Channel by Adding Hybrid Fillers
}

\author{
Chil-Chyuan Kuo ${ }^{1,2, *}$ and Wei-Hua Chen ${ }^{1}$ \\ 1 Department of Mechanical Engineering, Ming Chi University of Technology, New Taipei City 243, Taiwan; \\ M03118013@mail.mcut.edu.tw \\ 2 Research Center for Intelligent Medical Devices, Ming Chi University of Technology, No. 84, Gungjuan Road, \\ New Taipei City 243, Taiwan \\ * Correspondence: jacksonk@mail.mcut.edu.tw
}

check for updates

Citation: Kuo, C.-C.; Chen, W.-H. Improving Cooling Performance of Injection Molding Tool with Conformal Cooling Channel by Adding Hybrid Fillers. Polymers 2021 13, 1224. https://doi.org/10.3390/ polym 13081224

Academic Editor: Nitin Mehra

Received: 22 March 2021

Accepted: 9 April 2021

Published: 10 April 2021

Publisher's Note: MDPI stays neutral with regard to jurisdictional claims in published maps and institutional affiliations.

Copyright: (c) 2021 by the authors. Licensee MDPI, Basel, Switzerland. This article is an open access article distributed under the terms and conditions of the Creative Commons Attribution (CC BY) license (https:/ / creativecommons.org/licenses/by/ $4.0 /)$.

\begin{abstract}
Silicone rubber mold (SRM) is capable of reducing the cost and time in a new product development phase and has many applications for the pilot runs. Unfortunately, the SRM after injection molding has a poor cooling efficiency due to its low thermal conductivity. To improve the cooling efficiency, the thermal conductivity of the SRM was improved by adding fillers into the SRM. An optimal recipe for fabricating a high cooling efficiency low-pressure injection mold with conformal cooling channel fabricated by fused deposition modeling technology was proposed and implemented. This study proposes a recipe combining $52.6 \mathrm{wt}$. $\%$ aluminum powder, $5.3 \mathrm{wt} . \%$ graphite powder, and $42.1 \mathrm{wt}$ \% liquid silicon rubber can be used to make SRM with excellent cooling efficiency. The price-performance ratio of this SRM made by the proposed recipe is around 55. The thermal conductivity of the SRM made by the proposed recipe can be increased by up to $77.6 \%$ compared with convention SRM. In addition, the actual cooling time of the injection molded product can be shortened up to $69.1 \%$ compared with the conventional SRM. The actual cooling time obtained by the experiment is in good agreement with the simulation results with the relative error rate about $20 \%$.
\end{abstract}

Keywords: silicone rubber mold; thermal conductivity; filler; cooling time; relative error rate

\section{Introduction}

The digital manufacturing technology (DMT) plays an important role in the precision machinery. Additive manufacturing (AM) [1-4] is one of DMTs with some advantages, such as variety, complexity, flexibility, reducing energy usage, less materials waste, little lead time compared with conventional manufacturing processes. AM technology can provide the mold or die designers to verify a design in a matter of hours. Rapid tooling (RT) technology [5-8] is divided into soft or hard tooling. Tooling for low volume manufacturing runs is known as soft tooling (ST). The tools in ST are made from materials, such as silicone rubber or epoxy resin. According to the practical experience, the ST is easier to perform compared with conventional tooling steels. Among the ST technology, the silicone rubber mold (SRM) was often used to fabricate low-pressure wax injection molds (LPWIM) for manufacturing wax patterns with complex geometrical shapes since low-pressure wax injection molding is one of the common manufacturing processes for producing wax patterns [9-11]. Yuan et al. [12] investigated the rheological behavior of silicone rubber (SR) used in sheet metal flexible-die forming. It was found that the numerical analysis results of viscous pressure stretching are in good agreement with the experimental results. In addition, the higher viscous pressure can improve sheet formability. Wu et al. [13] investigated the macro-micro contact properties of SR by experiment and the finite element method. A new tester of macro contact properties of rubber seals was developed for measuring the contact area and contact force in real time. It was found that the simulation results are in good agreement with the experimental result. He et al. [14] developed a novel arc-spraying robot 
for rapid tooling. This robot can carry out the tooling process automatically and efficiently fully based on the sliced data of the master pattern. Rajaguru et al. [15] developed a rapid tooling for low-volume production of plastic parts using rapid prototyping technology and electroless nickel plating. The service life of the developed rapid tooling is longer under normal plastic processing conditions. Issa et al. [16] developed sensor elements for passively compliant gripper using conductive silicone rubber. It was found that the gripper can accommodate to any irregular and sensitive grasping object and carry light object. Ou et al. [17] investigated the filling and curing phases of bi-injection molding of liquid silicone rubbers.

It was found that the simulation results fit the shear viscosity behaviors of silicone LSR4350 well and the proposed Isayev-Deng model fits the curing kinetic reaction of elastomer materials well. Ou et al. [18] developed mathematical models for the thermokinetic parameters of silicone elastomers.

It was found that the simulation results predicted the mold filling and cure degree state into the die mold cavity accurately. Yang et al. [19] developed a microfabrication process to replicate high-aspect-ratio microstructures using silicone rubber micro molds. It was found that aspect ratio of 15:1 for a single piece and larger aspect ratio can be achieved. The proposed replication process provides low cost, mass production of high-aspect-ratio microstructures. Thian et al. [20] fabricated microfluidic channel using silicone rubber with vacuum casting. It was found that the casting of microfluidic channel via vacuum casting provides high repeatability. Glocke and Wiseman [21] fabricated micro-Fresnel zone plates using silicone rubber. A high quality $10-\mu \mathrm{m}$-thick zone plates having 100 zones and a 5- $\mu \mathrm{m}$-wide outer zone was fabricated. Christian et al. [22] fabricated a jawbone mold using silicone rubber. This study highlighted the importance of minimizing reactant viscosity in producing satisfactory polymer-glass bond. Ching et al. [23] fabricated a facial prosthetic model using silicone rubber. It was found that aesthetically matching and comfort of the prosthesis play a leading role to the success of prosthetic implants. This paper also presented a novel approach for making a prosthetic ear model. Maji et al. [24] developed a patient-specific craniofacial implant using rapid tooling technology. It was found that results of this study could assist a surgeon in preplanning an actual operation. Kozior et al. [25] presented the results of tests of surface waviness of samples made in the powder bed fusion technology with stainless steel powder. Results showed that the orientation of model arrangement has an impact on the quality of the technological surface texture. Kozior and Kundera [26] presented the research results of the surface texture measurement of models built by the fused deposition modeling (FDM) technology with ABS plastic. It was found that the direction of placing the models on the building platform affects the value of two-dimensional and spatial parameters of the geometric surface texture.

Generally, the injection molding involves filling, packing, cooling, and ejection four major stages. Especially, the cooling stage is the most dominant step of the cycle time. It is well known that the conformal cooling channel (CCC) provides better cooling performances than the conventional cooling channel. The productivity can be enhanced by the LPWIM with CCC [27] because the cooling can be reduced significantly during the cooling stage. Kanbur al. [28] reviewed the design and optimization of CCC for injection molding. This study also discussed the 3D models of CCC and relevant mold materials. Vojnova [29] introduced the benefits of molds with conformal cooling systems in the injection molding process. This study developed technological parameters on the quality of the injection molded parts by comparing the length of the production cycle based on cooling duration or individual types of cooling systems. Kitayama et al. [30] examined the cooling efficiency of conformal cooling channel in plastic injection molding (PIM) numerically and experimentally. It was found that the structural optimization is an important approach to determine the CCC. Holker and Tekkaya [31] developed extrusion dies with conformal cooling channels for increasing the productivity in the hot aluminum (Al) extrusion. It was found that the hybrid tools withstand the high mechanical and thermal loads which 
occur during hot aluminum extrusion. Lim et al. [32] proposed a method for designing the cooling channel by means of the energy balance principle and arrangement method. It was found that average tensile strengths of roof side products manufactured with the cooling times of 12 and $9 \mathrm{~s}$ were 1487 and $1488 \mathrm{MPa}$, respectively. Wang et al. [33] employed optimization of mold with spherical spiral conformal cooling system and product structure to reduce service stress of the injection molded products. This study indicated that geometrical structure should be designed according to the assembly and service conditions. In addition, molding defects, such as warpage, residual stress need to be considered in mechanical analysis. Brooks and Brigden proposed a concept for designing the conformal cooling layers with self-supporting lattices [34]. A case study of the injection molding of a plastic enclosure was used to compare the performance of conformal cooling layers with conventional cooling channels and conformal cooling channels. It was found that the conformal layers reduce the cooling time by $26.34 \%$ over conventional cooling channels.

However, the cooling efficiency of the mold made of SR was limited to the thermal conductivity of the materials. Therefore, enhancing the cooling efficiency of the SRM with CCC is an important research issue. In this study, a recipe for fabricating high cooling efficiency SRM was investigated. The five different fillers were added into the SRM to investigate the changes in thermal conductivity. The optimal recipe for fabricating SRM with high thermal conductivity was investigated experimentally and employed to fabricate high cooling efficiency SRM. In this study, the computer-aided engineering (CAE) simulation software named Moldex 3D was used since the design process of CCCs is difficult than the conventional cooling channels. The simulation software was used to predict cooling time of the injection molded product, part temperature distribution, mold temperature distribution, and warpage of the wax patterns. To validate the performance of the high cooling efficiency SRM, LPWIM were carried out for batch production of wax patterns.

\section{Experimental Details}

In this study, the product, SRM, and CCC were designed using SolidWorks software (SolidWizard Technology Inc, Taipei City, Taiwan). The injection molded product is a pipe end cap with dimensions of $32 \mathrm{~mm}$ in the upper outer diameter, $27 \mathrm{~mm}$ in the lower outer diameter, $17.5 \mathrm{~mm}$ in height, and $2.5 \mathrm{~mm}$ in wall thickness. The main reason for choosing the pipe end cap as an injection molded product is that the top edge of the water cup is set as a parting surface, which can easily disassemble the core and cavity inserts. Moreover, the CCC geometries designed for core and cavity insert do not overlap. Thus, choosing the pipe end cap as an injection molded product can demonstrate the substantial benefits of rapid injection tool with CCC. The process parameters for the simulation include filling time of $2.02 \mathrm{~s}$, injection pressure of $0.06 \mathrm{MPa}$, mold temperature of $25^{\circ} \mathrm{C}$, wax melting temperature of $99^{\circ} \mathrm{C}$, coolant temperatures of $25^{\circ} \mathrm{C}$, and an ejection temperature of $30^{\circ} \mathrm{C}$. To improve the thermal property of the SRM must be improved since it is a key factor on the cooling characteristics. In this study, five different fillers, namely aluminum (Al) powder, copper $(\mathrm{Cu})$ powder and graphite $(\mathrm{G})$ powder, iron $(\mathrm{Fe})$ powder, and carbon black $(\mathrm{CB})$ powder were added into the liquid silicone rubber to investigate the effects of different fillers on the thermal conductivity. Figure 1 shows the photos of $\mathrm{Al}$ and $\mathrm{G}$ powders. The average particle sizes of five different fillers are $48 \mu \mathrm{m}, 75 \mu \mathrm{m}, 13 \mu \mathrm{m}, 48 \mu \mathrm{m}$, and $28 \mu \mathrm{m}$, respectively. The material costs of Al, Cu, G, Fe, and CB powders are NTD 0.5/g, 0.19/g, 0.9/g, 0.8/g, and $0.53 / \mathrm{g}$, respectively. The CAE software named Moldex 3D (R16 SP3OR, CoreTech System Inc., New Taipei City, Taiwan) was employed to predict the cooling time of injection molded products, the mold temperature difference, the part temperature difference, and warpage of injection molded products. The standard process parameters for the simulation include injection pressure of $0.06 \mathrm{MPa}$, wax melting temperature of $99^{\circ} \mathrm{C}$, coolant flow rate of $130 \mathrm{cc} / \mathrm{s}$, inlet temperatures of $25^{\circ} \mathrm{C}$, and an ejection temperature of $30^{\circ} \mathrm{C}$. In this study, the boundary layer mesh was used to ensure the accuracy of simulation results because it is suitable for simulation models with intricate geometries. Based on the design guideline of 
CCC [35], the cooling channel diameter, the distance between the wall of cooling channel to the mold surface, and the pitch distance between central lines of cooling channels are $4 \mathrm{~mm}$, $7.5 \mathrm{~mm}$, and $17 \mathrm{~mm}$, respectively. Figure 2 shows the relationship of filling system, injection molded product and CCC of both core and cavity plates. In this study, the polyvinyl butyral (PVB) resin was selected as the material of CCC since it can be removed by methyl alcohol. The FDM machine (SAFEWAY 3D, New Taipei City, Taiwan) was used to fabricate the CCC because it provides the flexibility in the fabrication of complex CCC compared with conventional machining technologies. The process parameters for making the CCC are printing temperature of $190-210^{\circ} \mathrm{C}$, the hot bed temperature of $60^{\circ} \mathrm{C}$, the printing speed of $20 \mathrm{~mm} / \mathrm{s}$, and the layer thickness of $0.2 \mathrm{~mm}$. Figure 3 shows the schematic illustrations of the production process of a high cooling efficiency low-pressure injection mold with CCC. The silicone rubber (KE-1310ST, Shin Etsu Inc., Tokyo, Japan) and curing agent (CAT-1310S, Shin Etsu Inc., Tokyo, Japan) were mixed in a weight ratio of 10:1 to fabricate an SRM. A vacuum machine (F-600, Feiling, Inc., Taoyuan, Taiwan) was used to extract the air-bubbles resulting from the mixing process under vacuum conditions.

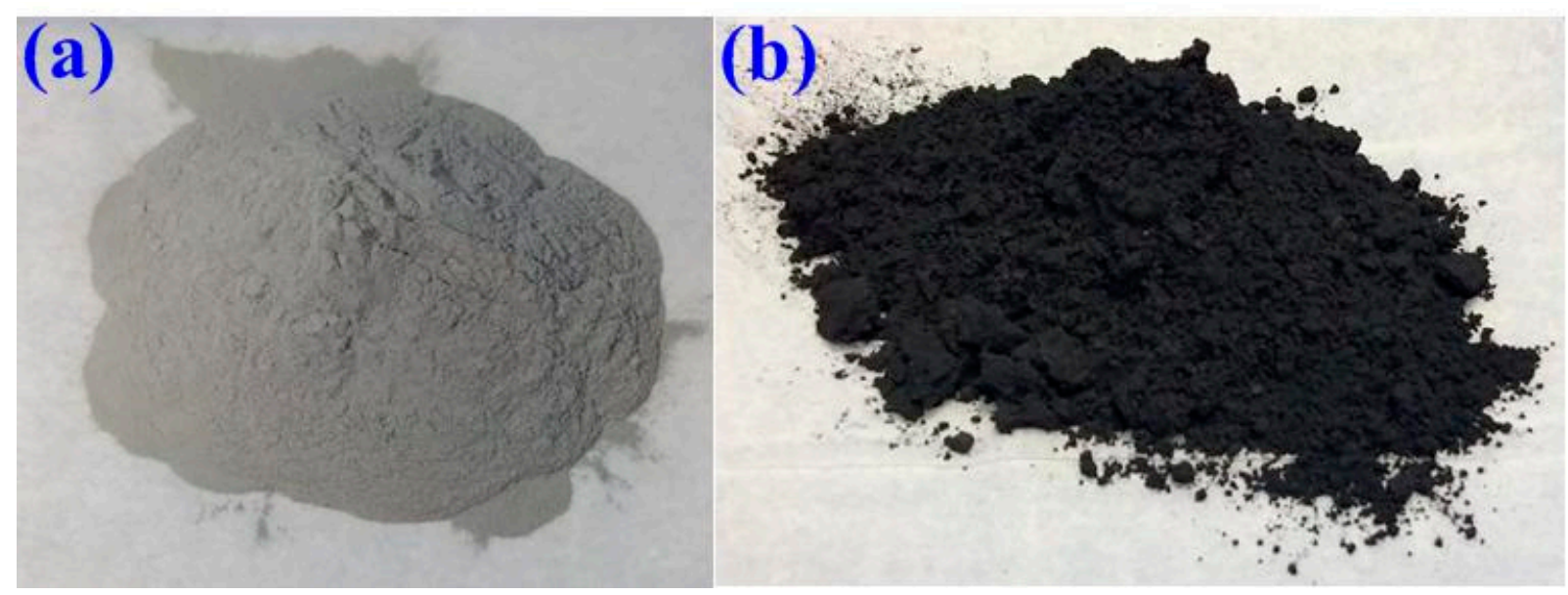

Figure 1. Photos of the (a) aluminum (Al) and (b) graphite $(\mathrm{G})$ powders.

Phase identification was carried out by X-ray diffraction (XRD) (D8 ADVANCE, Bruker Inc., New Taipei City, Taiwan). X-raying was performed in the geometry of a parallel beam with $\mathrm{Cu} \mathrm{K} \alpha$ radiation. In addition, the chemical composition of the fabricated SR molds was examined using an energy-dispersive $X$-ray spectroscopy (EDS). To investigate the thermal conductivity of the silicone rubber with different fillers, the thermal conductivity was carried out. The length, width and height of the test specimen are $25 \times 25 \times 25 \mathrm{~mm}^{3}$, respectively. The test specimens were placed on the top of the hot plate (YS-300S, YOTEC Inc., New Taipei City, Taiwan) and heated at $60^{\circ} \mathrm{C}$. The K-type thermocouple was placed on the top of the test specimens to record the temperature history using a data acquisition system (MRD-8002L, IDEA System Inc., Taoyuan, Taiwan). Figure 4 shows the experimental setup for measuring thermal conductivity of the silicone rubber with different fillers. In this study, the wax (K512, Kato Inc., Taoyuan, Taiwan) was used as molding materials. To investigate the cooling efficiency of the fabricated SRM with different fillers, the low-pressure wax injection molding was performed using a low-pressure wax injection machine (LPWIM) (0660, W\&W Inc., Taoyuan, Taiwan). To validate the performance of the high cooling performance SRM with CCC, an experimental setup was developed and implemented. This system was composed of three k-type thermocouples (C071009-079, Cheng Tay Inc., New Taipei City, Taiwan), a water reservoir with a thermo-electric cooler (TEC12706AJ, Caijia Inc., New Taipei City, Taiwan), a temperature controller (JCM-33A, Shinko Inc., New Taipei City, Taiwan), and a data acquisition system. The water was used as cooling medium in this study. The inlet coolant temperature was kept at room temperature. Temperature histories of the molded wax patterns were recorded by a data 
acquisition system. The ejection temperature of the molded wax patterns was set at $30^{\circ} \mathrm{C}$ via a series of test runs. The cooling time can be determined according to the temperature histories of the molded wax patterns after LPWIM.
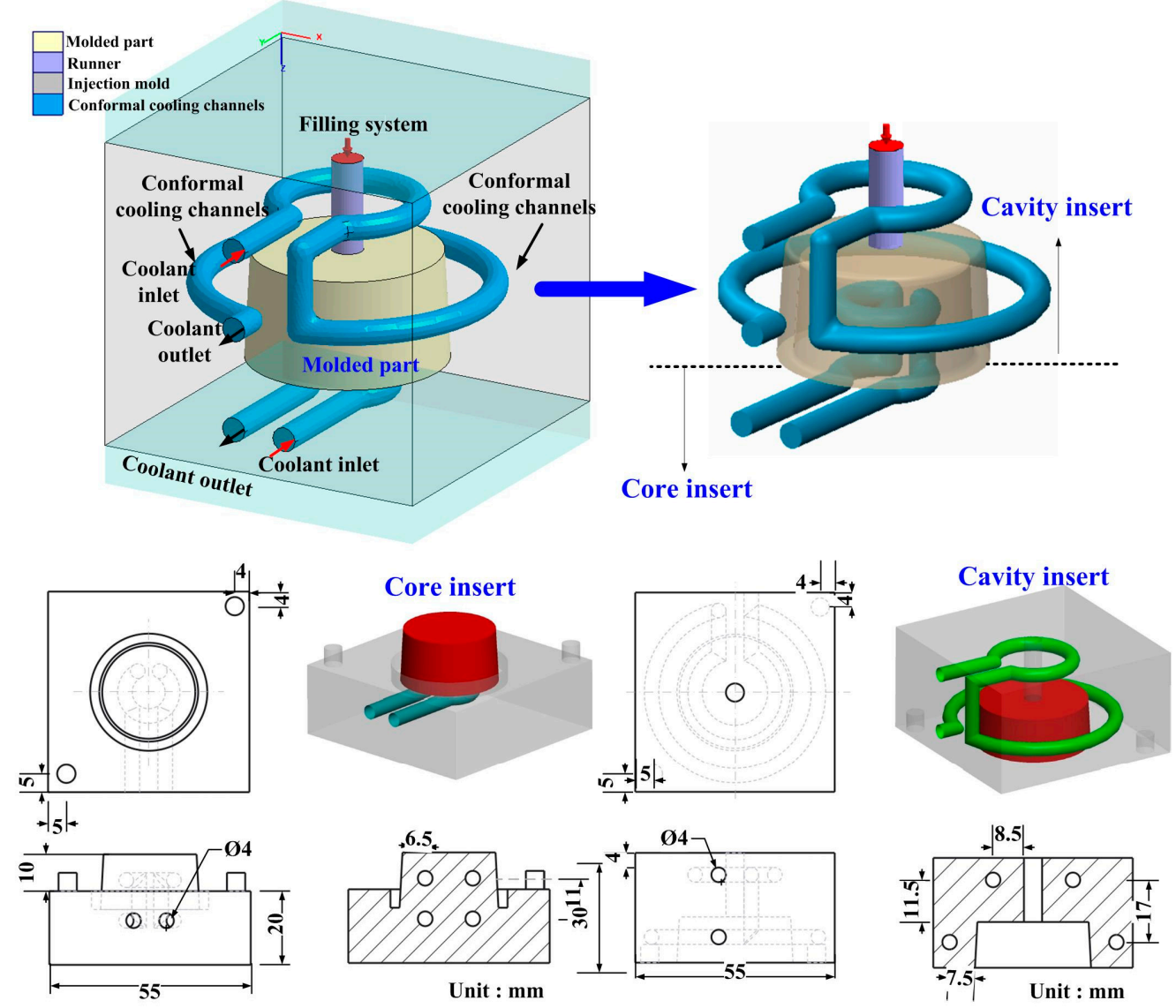

Figure 2. Relationship of filling system, injection molded product and conformal cooling channel (CCC) of both core and cavity plates.

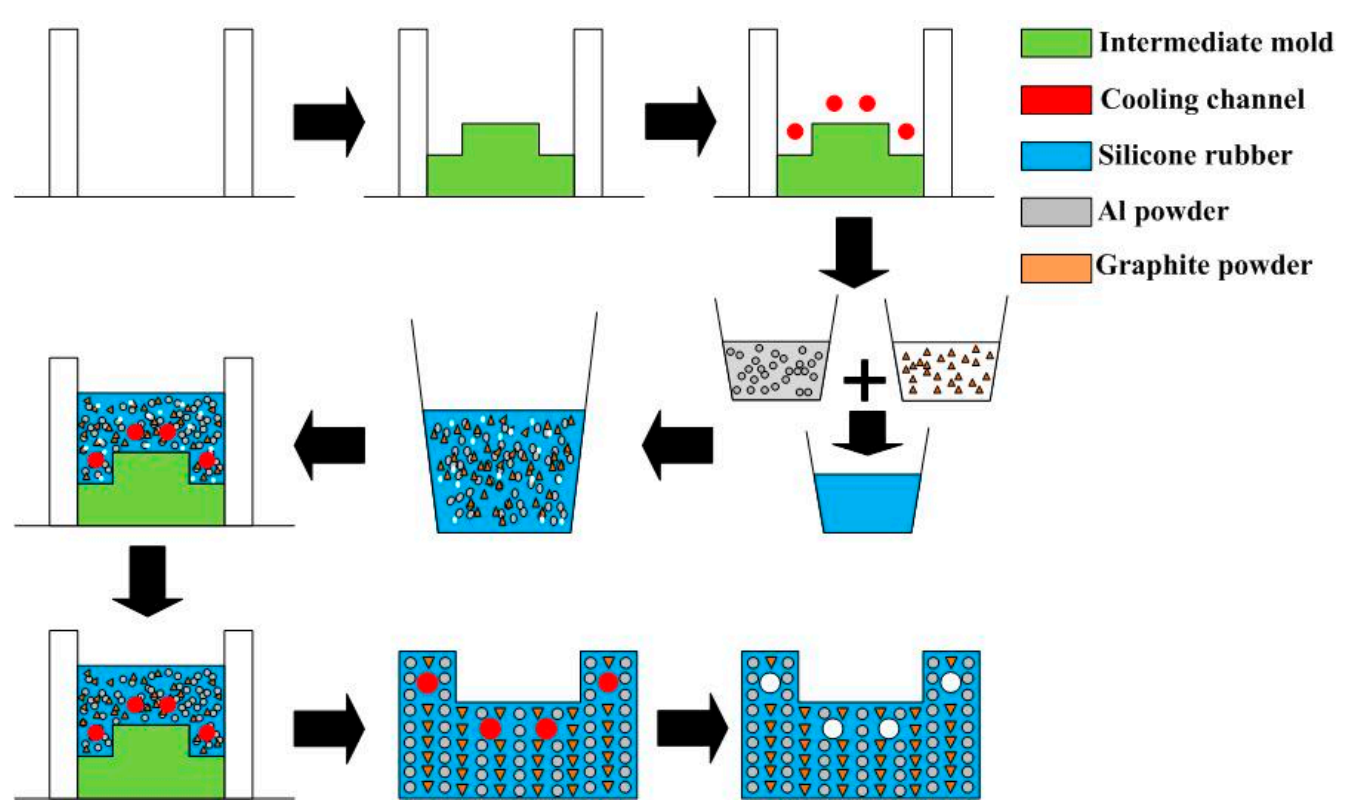

Figure 3. Schematic illustrations of the production process of a high cooling efficiency low-pressure injection mold with CCC. 

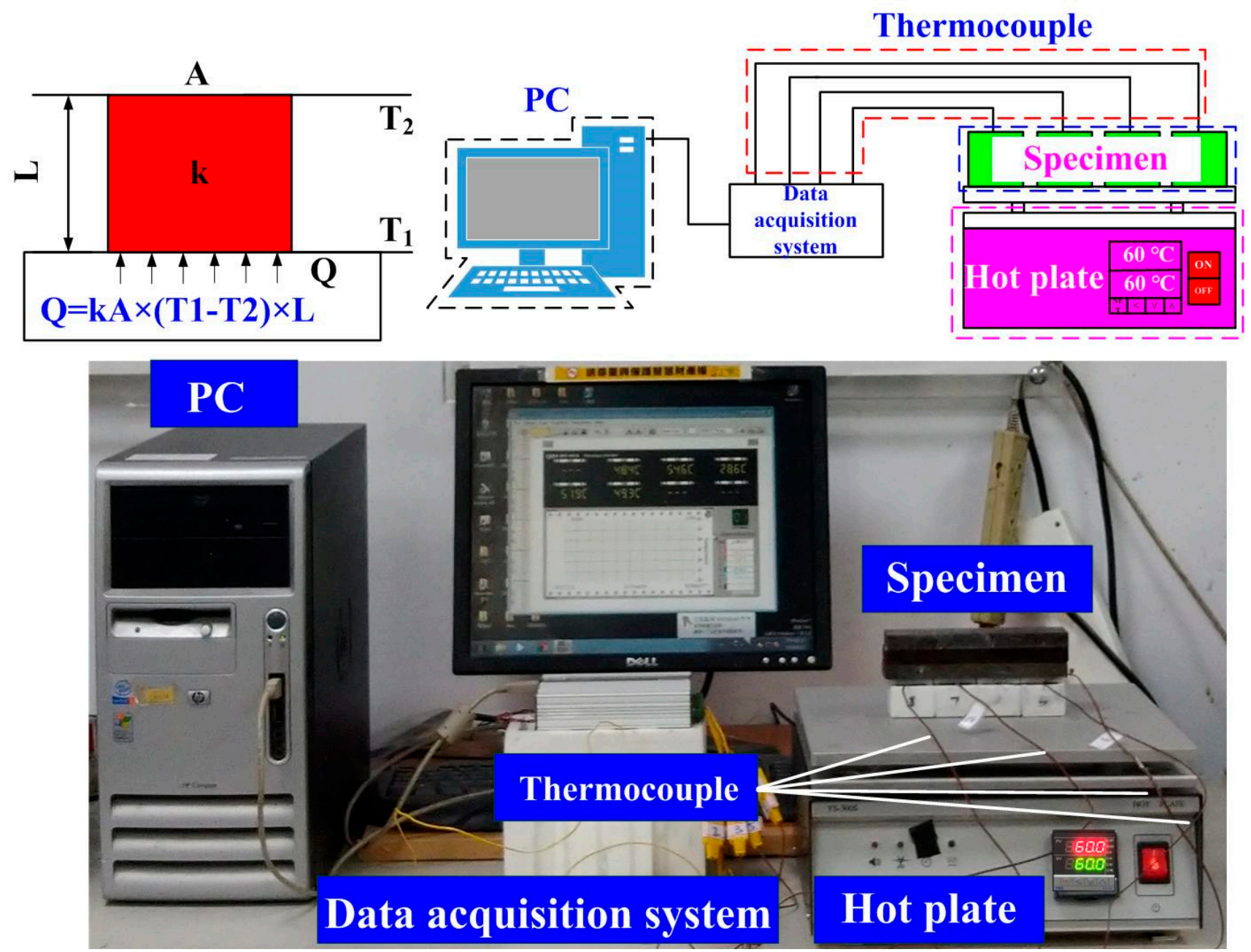

Figure 4. Experimental setup for measuring thermal conductivity of the silicone rubber with different fillers.

\section{Results and Discussion}

According to preliminary experiments [36], the thermal conductivity of pure silicone rubber is approximately $21.4 \mathrm{~W} / \mathrm{m}-\mathrm{K}$. The thermal conductivities of the silicone rubber with $60 \mathrm{wt} . \% \mathrm{Al}$ powder, $80 \mathrm{wt} . \%$ Fe powder, $70 \mathrm{wt} . \% \mathrm{Cu}$ powder, $20 \mathrm{wt} . \% \mathrm{G}$ powder, and 15 wt. $\%$ CB powder are approximately $29.4 \mathrm{~W} / \mathrm{m}-\mathrm{K}, 41.3 \mathrm{~W} / \mathrm{m}-\mathrm{K}, 36.9 \mathrm{~W} / \mathrm{m}-\mathrm{K}$, $33.0 \mathrm{~W} / \mathrm{m}-\mathrm{K}$, and $23.4 \mathrm{~W} / \mathrm{m}-\mathrm{K}$, respectively. Three phenomena were found: (a) the thermal conductivity of the SRM was improved significantly when $80 \mathrm{wt} . \%$ Fe powder was added into SR. However, the SRM affected by the coolant is prone to rust when the Fe powder was selected as filler. This drawback of the SRM will affect the cooling performance in the LPWIM; (b) the thermal conductivity of the SRM was not improved greatly when the CB powder was selected as filler. Improvement in thermal conductivity of the SRM is only about $9.3 \%$; (c) the thermal conductivity of the SRM was improved to $36.9 \mathrm{~W} / \mathrm{m}-\mathrm{K}$ when the $\mathrm{Cu}$ powder was selected as filler. However, the cost of $\mathrm{Cu}$ powder is expensive compared with other powders. Based on the above analysis, $\mathrm{Al}$ and $\mathrm{G}$ powders were selected as filler to develop high cooling efficiency SRM with CCC. Table 1 shows the planning table for silicon rubber adding different weight ratios of $\mathrm{Al}$ powder and $\mathrm{G}$ powder. Figure 5 shows the recipe as a function of thermal conductivity. According to the thermal conductivity, the SRM made with the recipes 3, 5, 7, and 9 is the first priority due to higher thermal conductivity. The SRM made with the recipes 2, 4, 6, and 8 is the second priority due to lower thermal conductivity. 
Table 1. Planning table for silicon rubber adding different weight ratios of $\mathrm{Al}$ powder and $\mathrm{G}$ powder.

\begin{tabular}{ccccccc}
\hline \multirow{2}{*}{ Recipe } & Al Powder & G Powder & SR & \multicolumn{3}{c}{ wt. \% } \\
\cline { 2 - 7 } & $\mathbf{g}$ & $\mathbf{g}$ & $\mathbf{g}$ & Al & G & Silicone Rubber \\
\hline 1 & 60 & 0 & 40 & 60.0 & 0 & 40.0 \\
\hline 2 & 60 & 5 & 40 & 57.1 & 4.8 & 38.1 \\
\hline 3 & 60 & 10 & 40 & 54.5 & 9.1 & 36.4 \\
\hline 4 & 50 & 5 & 40 & 52.6 & 5.3 & 42.1 \\
\hline 5 & 50 & 10 & 40 & 50.0 & 10.0 & 40.0 \\
\hline 6 & 40 & 5 & 40 & 47.1 & 5.9 & 47.1 \\
\hline 7 & 40 & 10 & 40 & 44.4 & 11.1 & 44.4 \\
\hline 8 & 30 & 5 & 40 & 40.0 & 6.7 & 53.3 \\
\hline 9 & 30 & 10 & 40 & 37.5 & 12.5 & 50.0 \\
\hline
\end{tabular}

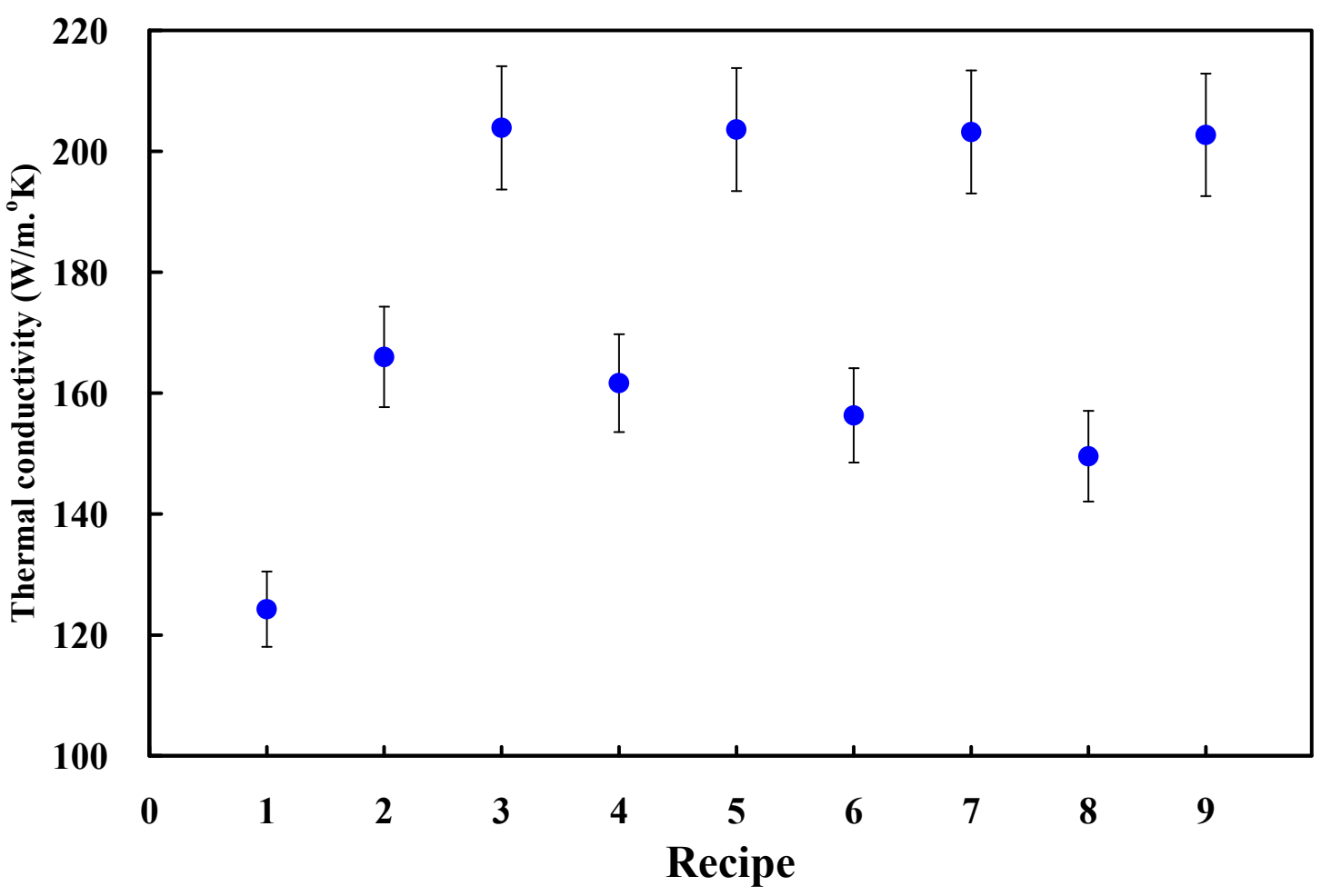

Figure 5. Recipe as a function of thermal conductivity.

Figure 6 shows the top view of the specimens made with recipes 3, 5, 7, and 9. The results showed that the specimens made with recipes $3,5,7$, and 9 cannot be formed into cubic due to the poor fluidity of the mixture. Figure 7 shows the specimens made with recipes 6,4 , and 2 . As can be seen, specimens can be formed into cubic successfully using recipes 6,4 , and 2 . This means that recipes $3,5,7$, and 9 can be used to fabricate high cooling efficiency SRM.

Figure 8 shows the XRD patterns of the specimens made with recipes 6,4 , and 2 . The results clearly found that the stronger the signal strength of $\mathrm{Al}$ and $\mathrm{G}$ powders in the EDS spectrum stands for the more $\mathrm{Al}$ and $\mathrm{G}$ powders added to the SRM. To understand the dispersion of $\mathrm{Al}$ and $\mathrm{G}$ powders of the specimens made with recipes 6, 4, and 2, three positions, namely top, middle, and bottom were conducted by EDS. Figure 9 shows the EDS images of the specimens made with recipes 6, 4, and 2. As can be seen, the $\mathrm{Al}$ and $\mathrm{G}$ powders were distributed uniformly inside the specimens made with recipes 6,4 , and 2 . 
This result indicates that no any agglomeration [37] and precipitation [38] of the $\mathrm{Al}$ and G powders inside the specimens were found.

(a)

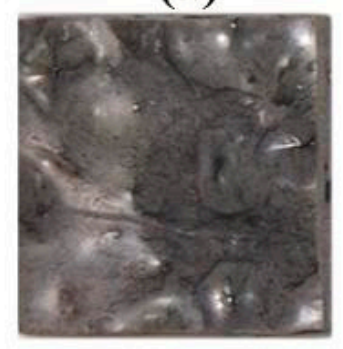

(b)

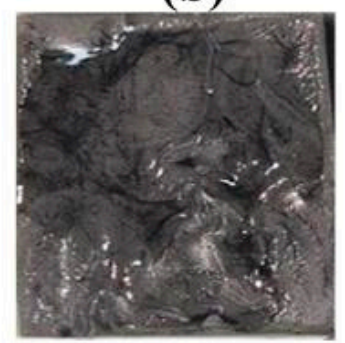

(c)

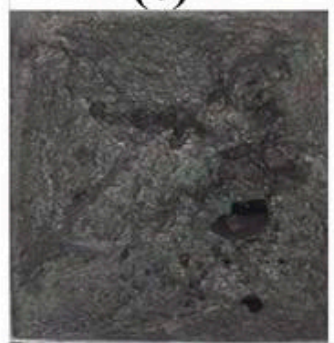

(d)

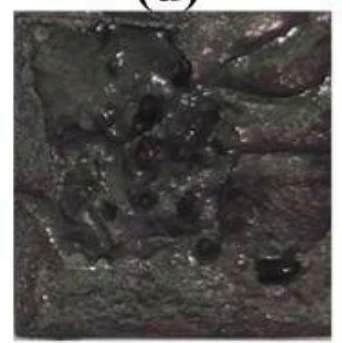

Figure 6. Top view of the specimens made with recipes (a) 3, (b) 5, (c) 7, and (d) 9.

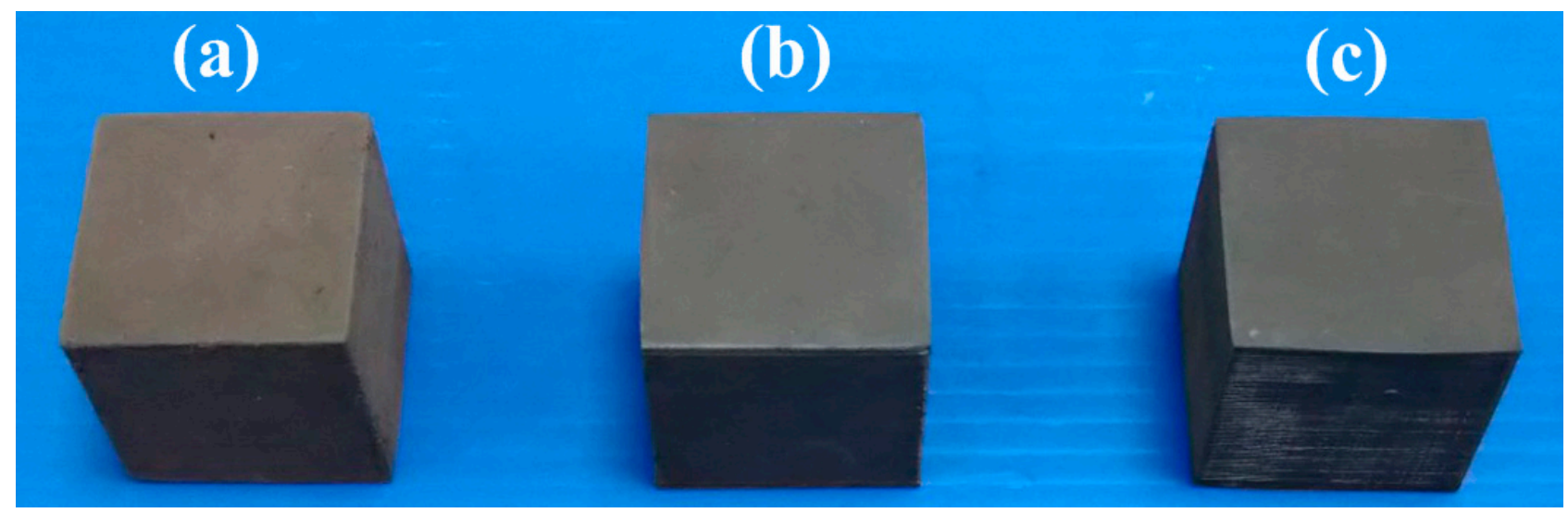

Figure 7. Specimens made with recipes (a) 6, (b) 4, and (c) 2 .

To understand the thermal conductivity of specimens, four different kinds of specimens were used to study. The heating temperature was fixed at $60{ }^{\circ} \mathrm{C}$, and the test piece was heated and measured for $3 \mathrm{~h}$. Figure 10 shows the top temperature of the specimens as a function of time. The highest top temperature of the specimen made with $60 \mathrm{wt} \% \mathrm{Al}$ powder, recipe 6 , recipe 4 , and recipe 2 are about $47.2^{\circ} \mathrm{C}, 49.6{ }^{\circ} \mathrm{C}, 50.1{ }^{\circ} \mathrm{C}$, and $49.0^{\circ} \mathrm{C}$, respectively. The thermal conductivities of the specimen made with $60 \mathrm{wt} \% \mathrm{Al}$ powder, recipe 6 , recipe 4 , and, recipe 2 are about $29.4 \mathrm{~W} / \mathrm{m}-\mathrm{k}, 34.2 \mathrm{~W} / \mathrm{m}-\mathrm{k}, 38.0 \mathrm{~W} / \mathrm{m}-\mathrm{k}$, and $36.2 \mathrm{~W} / \mathrm{m}-\mathrm{k}$, respectively. It was found that the thermal conductivity of the specimen made with recipe 4 was the highest. As can be seen, a significant improvement in the thermal conductivity about $77.6 \%$ can be obtained. The recipe 4 is composed of $52.6 \mathrm{wt} . \%$ Al powder, 5.3 wt. $\%$ G powder, and 42.1 wt.\% liquid silicon rubber. Therefore, recipe 4 was used to fabricate the high cooling efficiency SRM. According to the thermal conductivity obtained, the simulation software entitled Moldex 3D was then employed to predict cooling time of the injection molded product, part temperature distribution, mold temperature distribution, and warpage of the wax patterns. In this study, the three-dimensional tetrahedron elements were selected because it has linear interpolation shape functions [39]. To investigate the optimal number of meshes, the mesh independent study was carried out with fifteen different numbers of meshes. Figure 11 shows the number of meshes as a function of the cooling time of the injection molded product. As can be seen, the cooling time of the injection molded product reached convergence when the mesh element counts exceed 1071.508. Thus, the mesh with 1071.508 cells was selected as the mesh structure based on both the correctness of the cooling time and the computing time. 

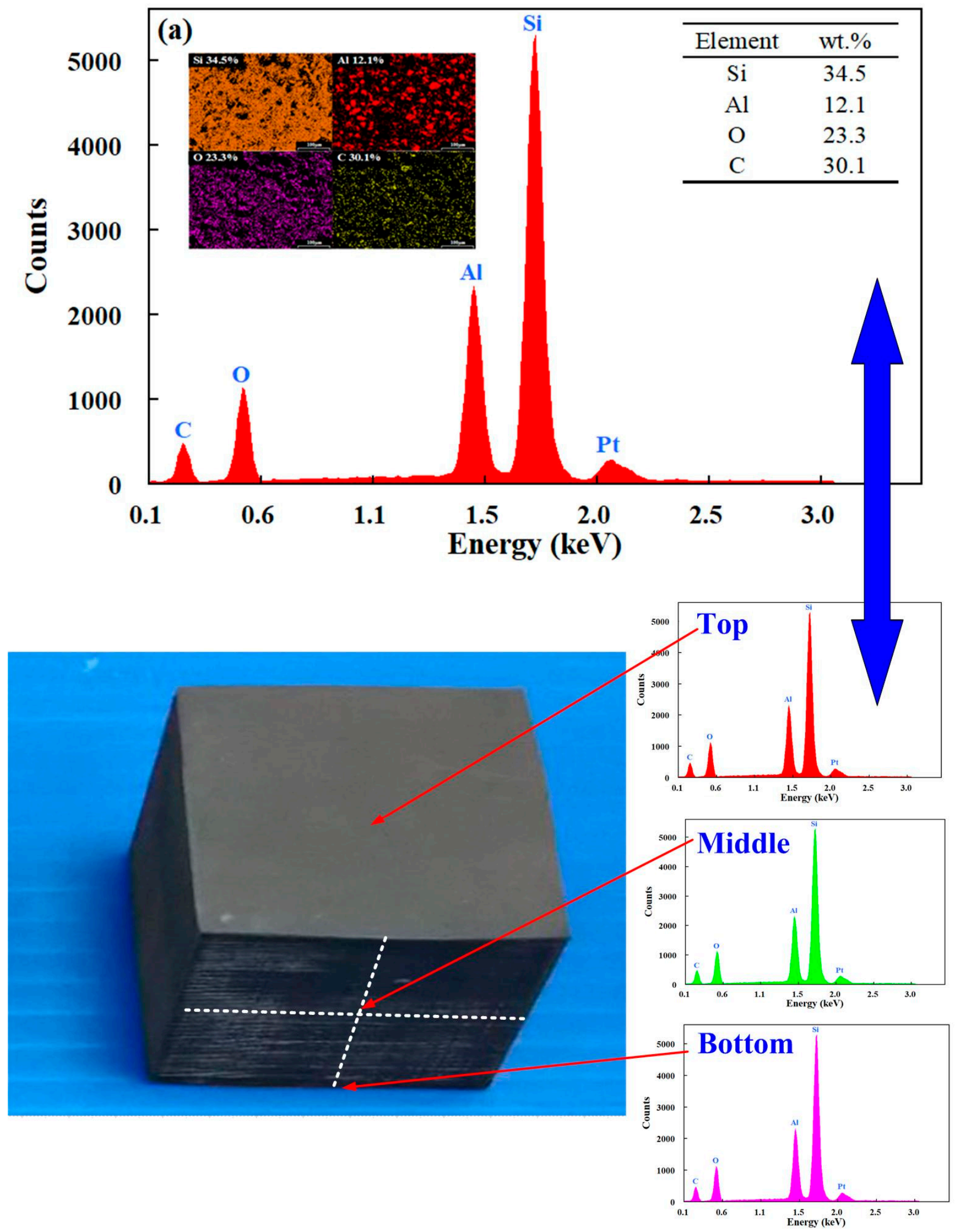

Figure 8. Cont. 

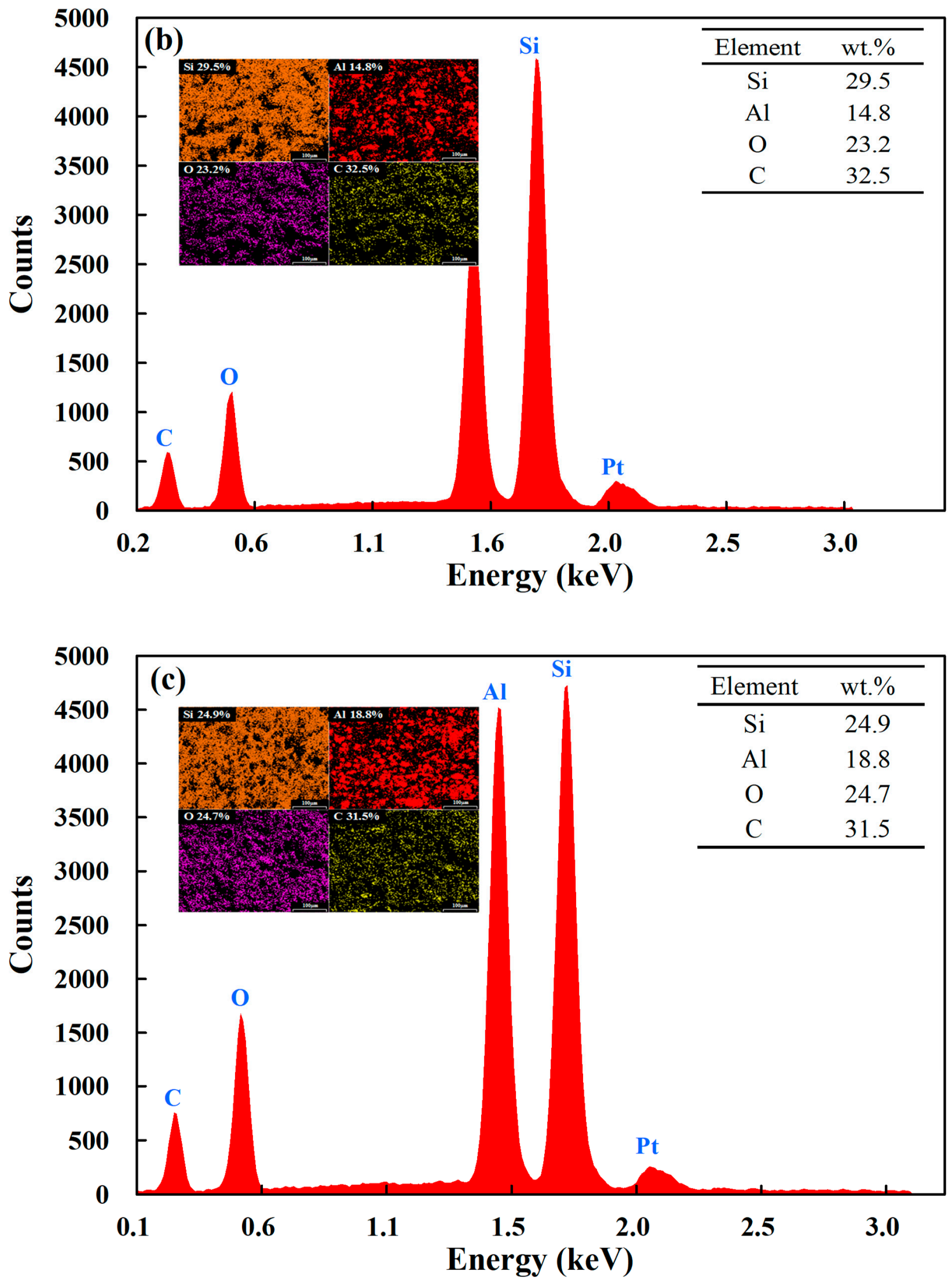

Figure 8. X-ray diffraction (XRD) patterns of the specimens made with recipes (a) 6, (b) 4, and (c) 2. 
(a)

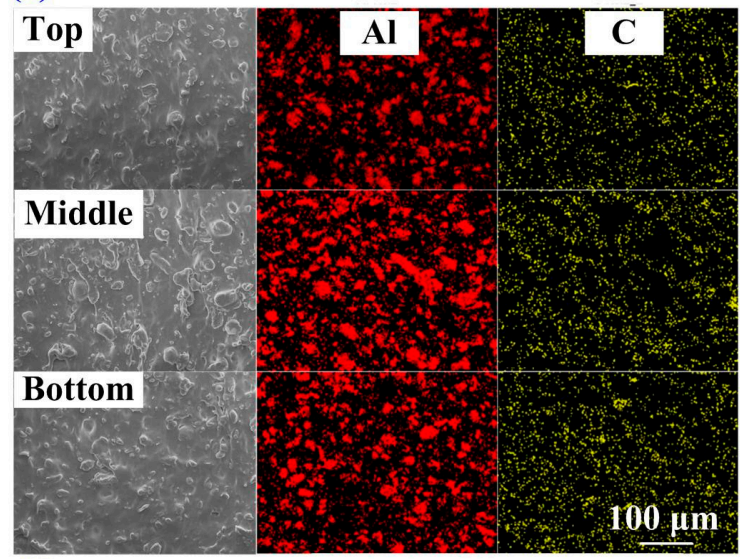

(c)

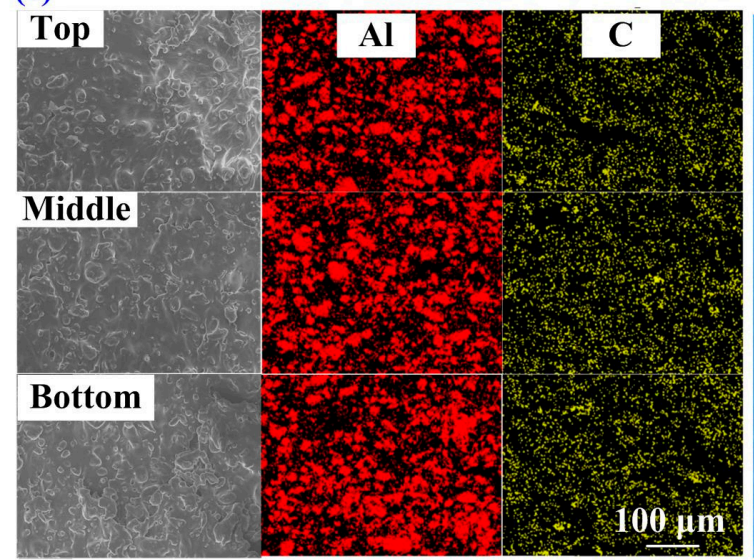

(b)
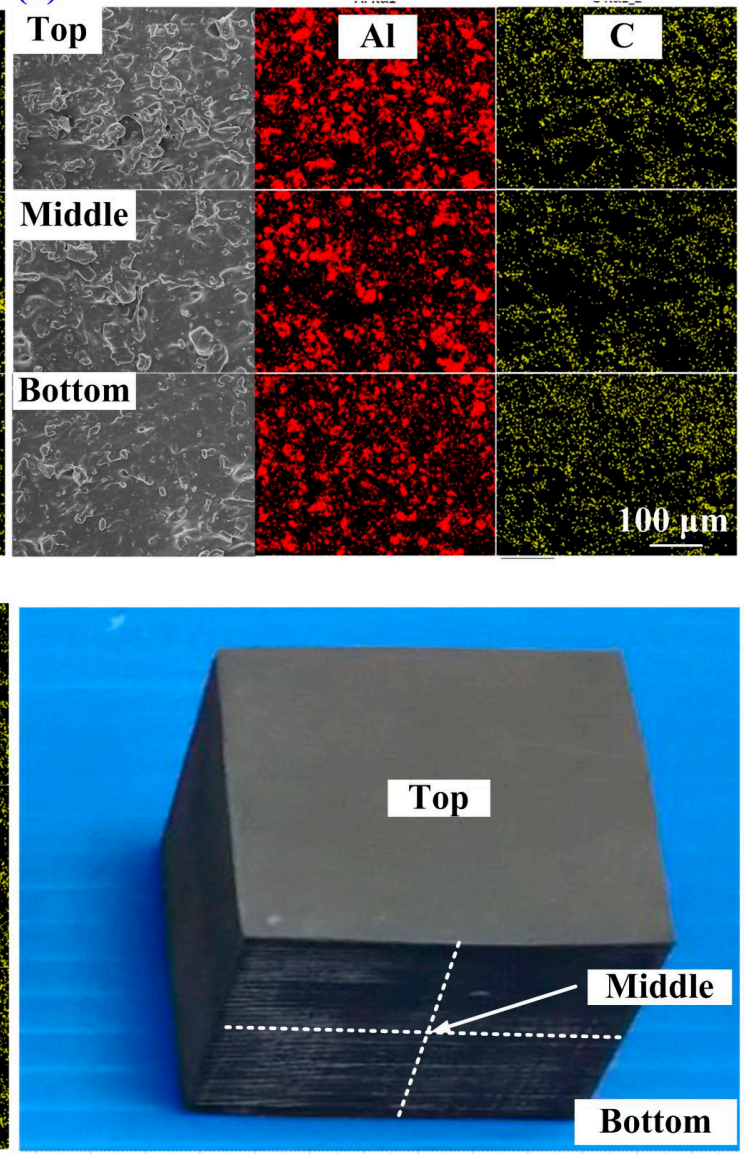

Figure 9. Energy-dispersive X-ray spectroscopy (EDS) images of the specimens made with recipes (a) 6, (b) 4, and (c) 2.

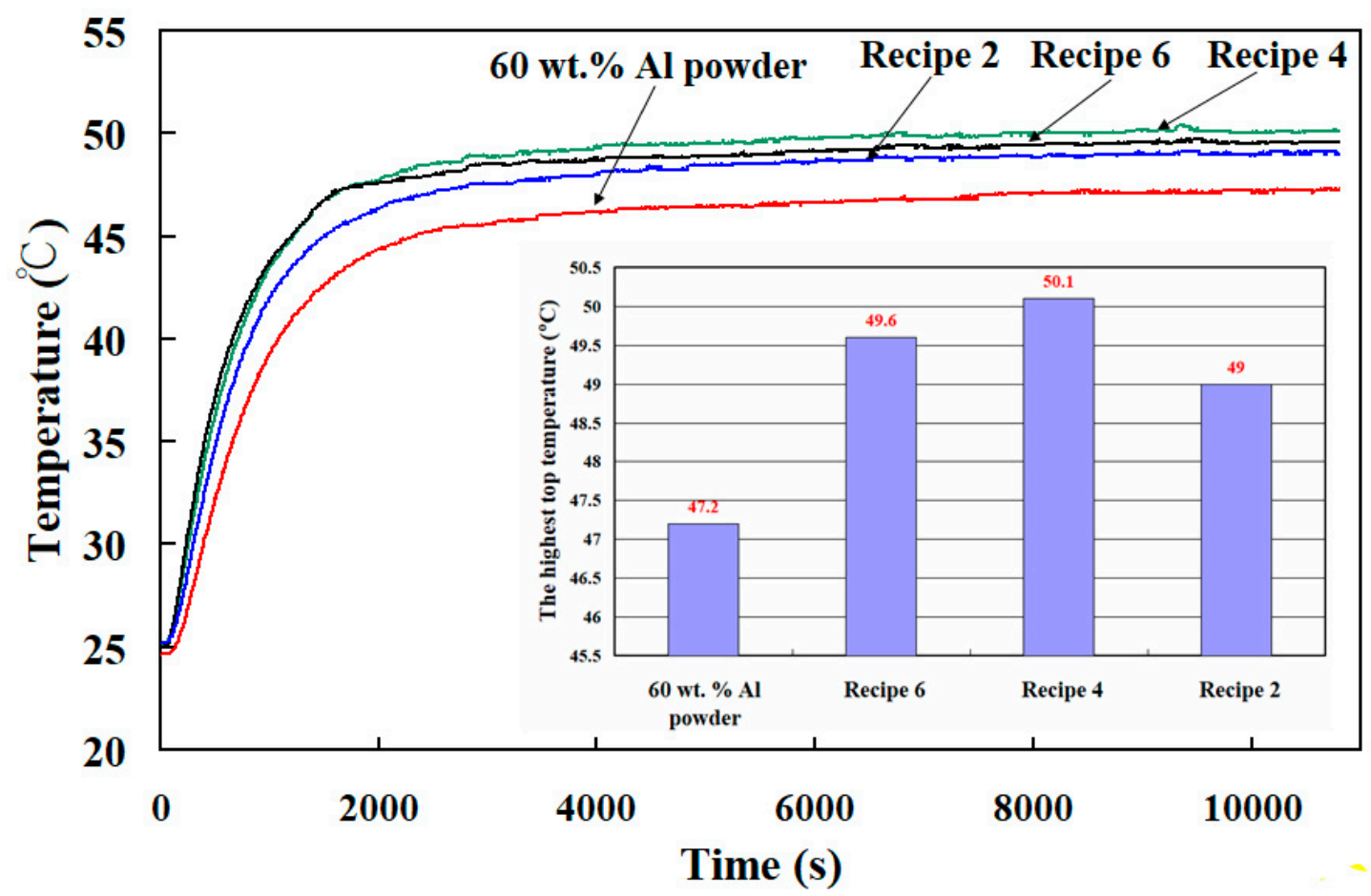

Figure 10. The top temperature of the specimens as a function of time. 


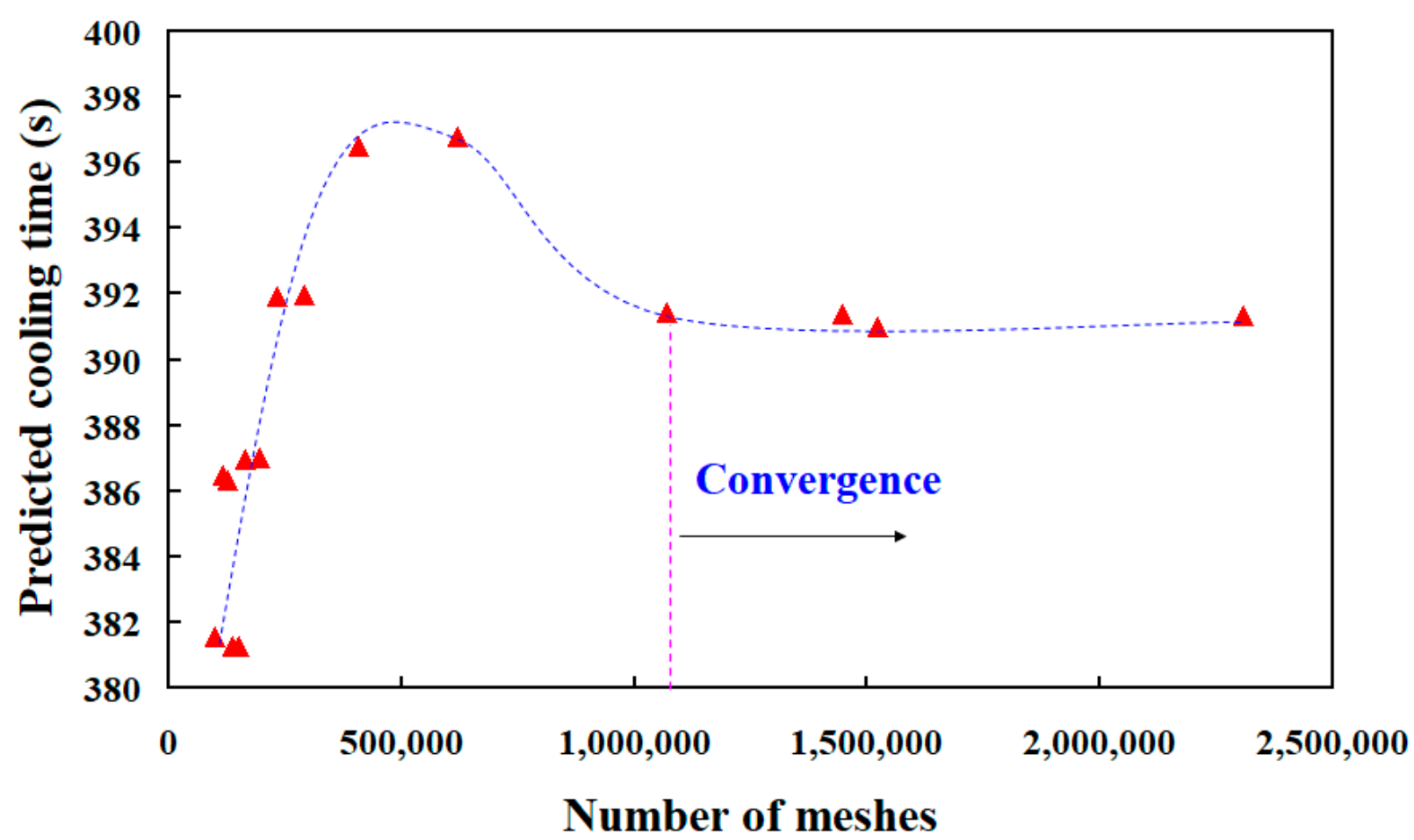

Figure 11. Number of meshes as a function of the cooling time of the injection molded product.

Figure 12 shows the numerical simulation results of the part temperature difference for conventional SRM, SRM with $60 \mathrm{wt} . \% \mathrm{Al}$ powder, and SRM made with recipe 4 . The part surface temperature distributions of conventional SRM, SRM with $60 \mathrm{wt} . \%$ Al powder, and SRM made with recipe 4 are $24.616-30.907^{\circ} \mathrm{C}, 26.000-30.753^{\circ} \mathrm{C}$, and $26.218-30.940{ }^{\circ} \mathrm{C}$, respectively. As can be seen, the part temperature differences for conventional SRM, SRM with $60 \mathrm{wt} . \% \mathrm{Al}$ powder, and SRM made with recipe 4 are $6.291{ }^{\circ} \mathrm{C}, 4.753^{\circ} \mathrm{C}$, and $4.722^{\circ} \mathrm{C}$, respectively. This means that the part temperature difference for SRM made with recipe 4 has the lowest surface temperature difference of the molded part. Mold temperature difference stands for the temperature difference between the cavity plate and core plate. Generally, large mold temperature difference will result in part warpage. Figure 13 shows the numerical simulation results of the mold temperature difference for conventional SRM, SRM with $60 \mathrm{wt} . \% \mathrm{Al}$ powder, and SRM made with recipe 4 . The mold surface temperature distributions of conventional SRM, SRM with $60 \mathrm{wt} . \% \mathrm{Al}$ powder, and SRM made with recipe 4 are $25.002-33.601{ }^{\circ} \mathrm{C}, 25.002-32.955^{\circ} \mathrm{C}$, and $25.003-32.249^{\circ} \mathrm{C}$, respectively. The mold temperature differences for conventional SRM, SRM with $60 \mathrm{wt} . \% \mathrm{Al}$ powder, and SRM made with recipe 4 are $8.599{ }^{\circ} \mathrm{C}, 7.953^{\circ} \mathrm{C}$, and $7.246{ }^{\circ} \mathrm{C}$, respectively. It is interesting to note that the mold surface temperature difference of the SRM made with recipe 4 is the lowest because the heat of the injected product can be absorbed and dissipated efficiently to the mold due to high thermal conductivity. This means that lower difference in the mold surface temperature difference will help improve the quality of the molded parts will be due to less warpage [40-42]. Figure 14 shows the numerical simulation results of the warpage of the molded parts for conventional SRM, SRM with $60 \mathrm{wt} . \% \mathrm{Al}$ powder, and SRM made with recipe 4 . The total displacements of the molded parts for conventional SRM, SRM with $60 \mathrm{wt} . \% \mathrm{Al}$ powder, and SRM made with recipe 4 are $1.791 \times 10^{-2} \mathrm{~mm}, 2.879 \times 10^{-2} \mathrm{~mm}$, and $3.876 \times 10^{-2} \mathrm{~mm}$, respectively. As can be seen, the SRM made with recipe 4 has larger warpage [43] since it was attributed to the higher volumetric shrinkage [44,45] caused by higher gate solidification speed [46,47] during the solidification stage of the molded part. This disadvantage can be solved by controlling packing pressure [48-50] appropriately during the packing stage for an injection mold with high cooling efficiency before demolding of the molded parts. 


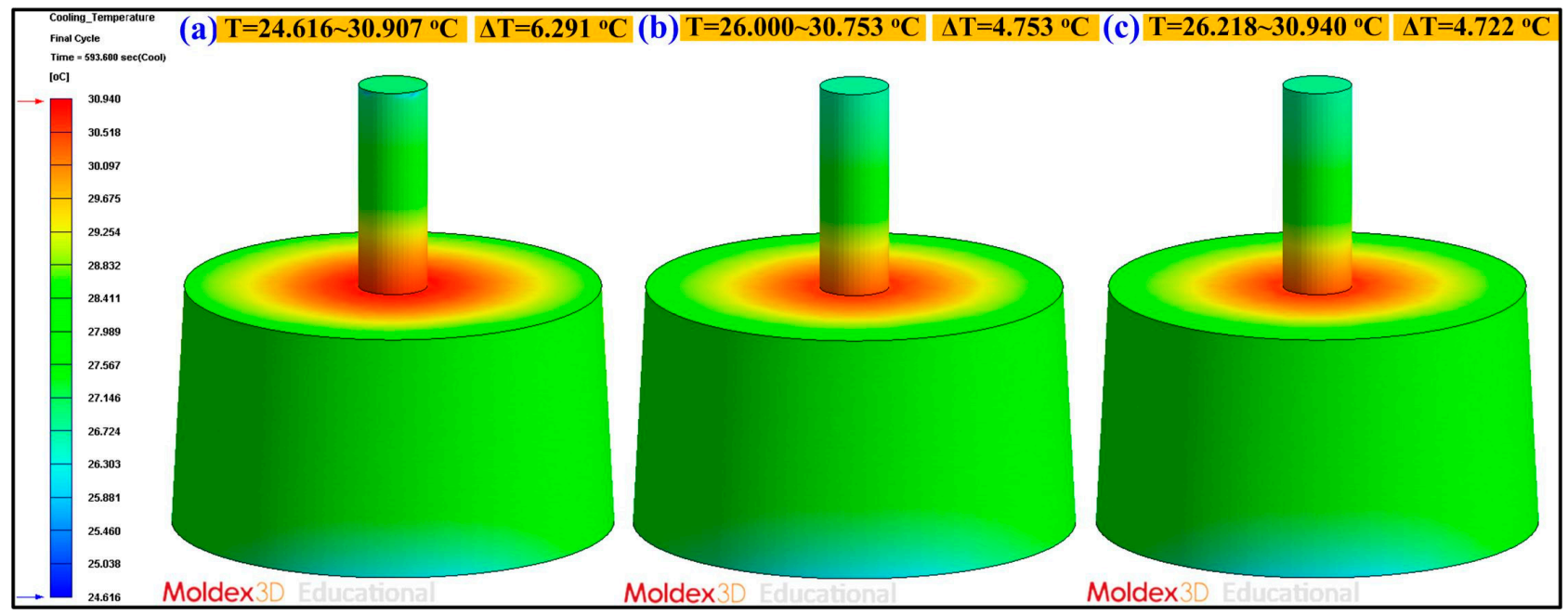

Figure 12. Numerical simulation results of the part temperature difference for (a) conventional silicone rubber mold (SRM), (b) SRM with 60 wt.\% Al powder, (c) SRM made with recipe 4.

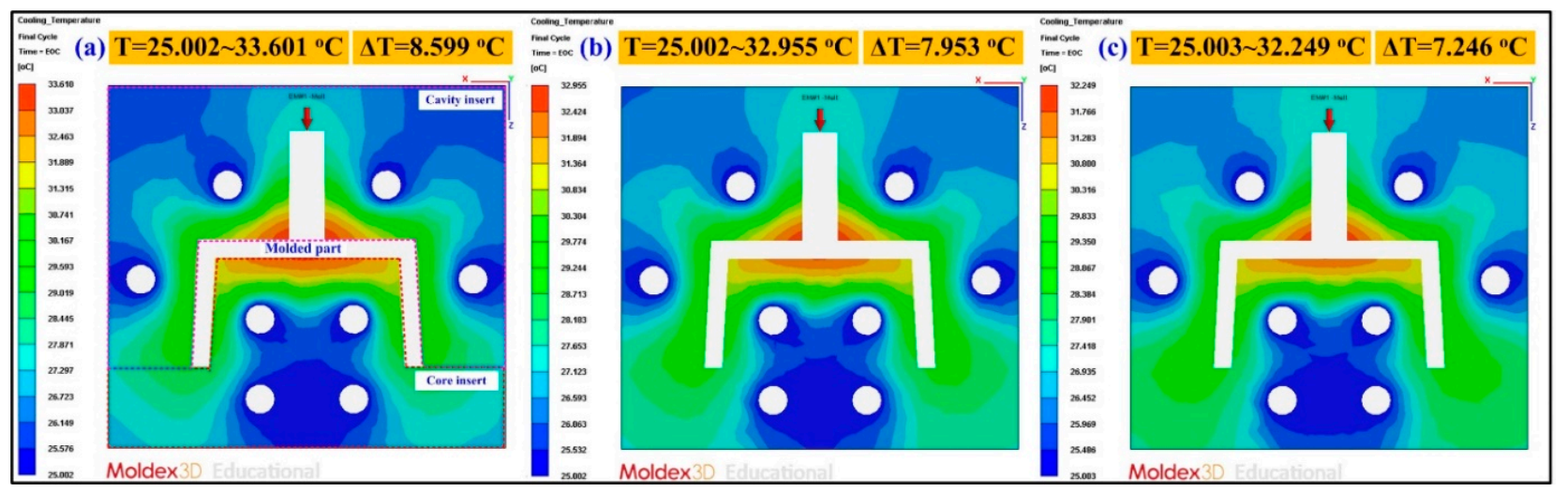

Figure 13. Numerical simulation results of the mold temperature difference for (a) conventional SRM, (b) SRM with 60 wt.\% Al powder, (c) SRM made with recipe 4.

Cooling channel pressure result reveals the pressure distribution inside the cooling channels. In general, higher pressure in the coolant means higher energy in pumping to maintain the flow rate and cooling efficiency. The coolant temperature difference indicates the difference between the highest coolant temperature and the lowest coolant temperature. Figure 15 shows the numerical simulation results of the coolant temperature difference for conventional SRM, SRM with $60 \mathrm{wt} . \% \mathrm{Al}$ powder, and SRM made with recipe 4 . The coolant temperature difference was about $0.15^{\circ} \mathrm{C}$. As can be seen, there is no significant difference in the coolant temperature difference between three molds. Figure 16 shows the numerical simulation results of the coolant pressure difference for conventional SRM, SRM with $60 \mathrm{wt} . \% \mathrm{Al}$ powder, and SRM made with recipe 4 . The coolant pressure difference was about $0.21 \mathrm{MPa}$. As can be seen, there is no significant difference in the coolant pressure difference between three molds. According to the results described above, this means the layout of the CCC is appropriate. Figure 17 shows the numerical simulation results of the temperature of the molded wax pattern as a function of the cooling time. The cooling time of the injection molded product for conventional SRM, SRM with $60 \mathrm{wt} . \% \mathrm{Al}$ powder, and SRM made with recipe 4 are around $601 \mathrm{~s}, 286 \mathrm{~s}$, and $221 \mathrm{~s}$, respectively. It was found that SRM made with recipe 4 can save the cooling time of the injection molded product about $380 \mathrm{~s}$ compared with the conventional SRM. Figure 18 shows the SRM made with recipe 4. 


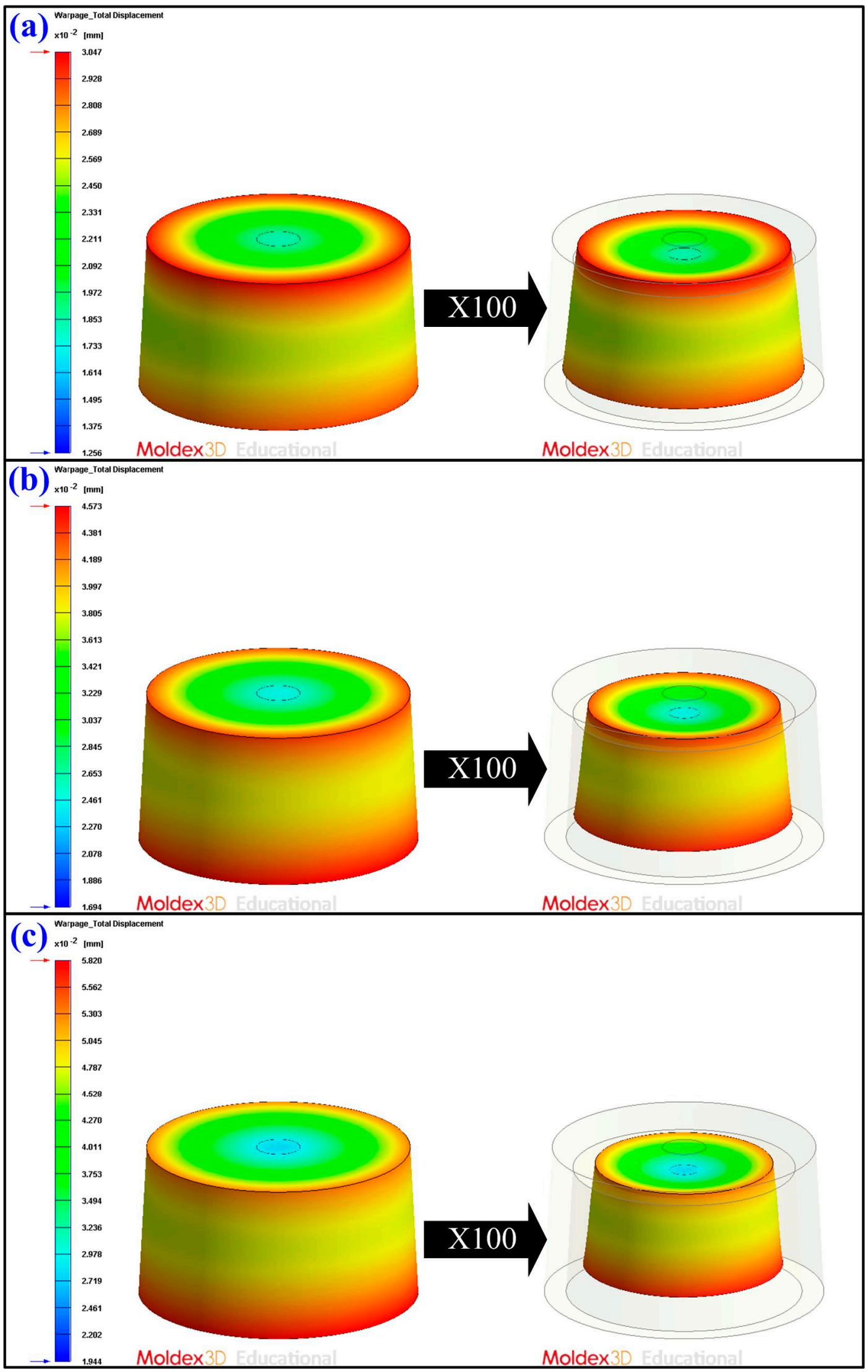

Figure 14. Numerical simulation results of the warpage of the molded parts for (a) conventional SRM, (b) SRM with 60 wt.\% Al powder, (c) SRM made with recipe 4. 


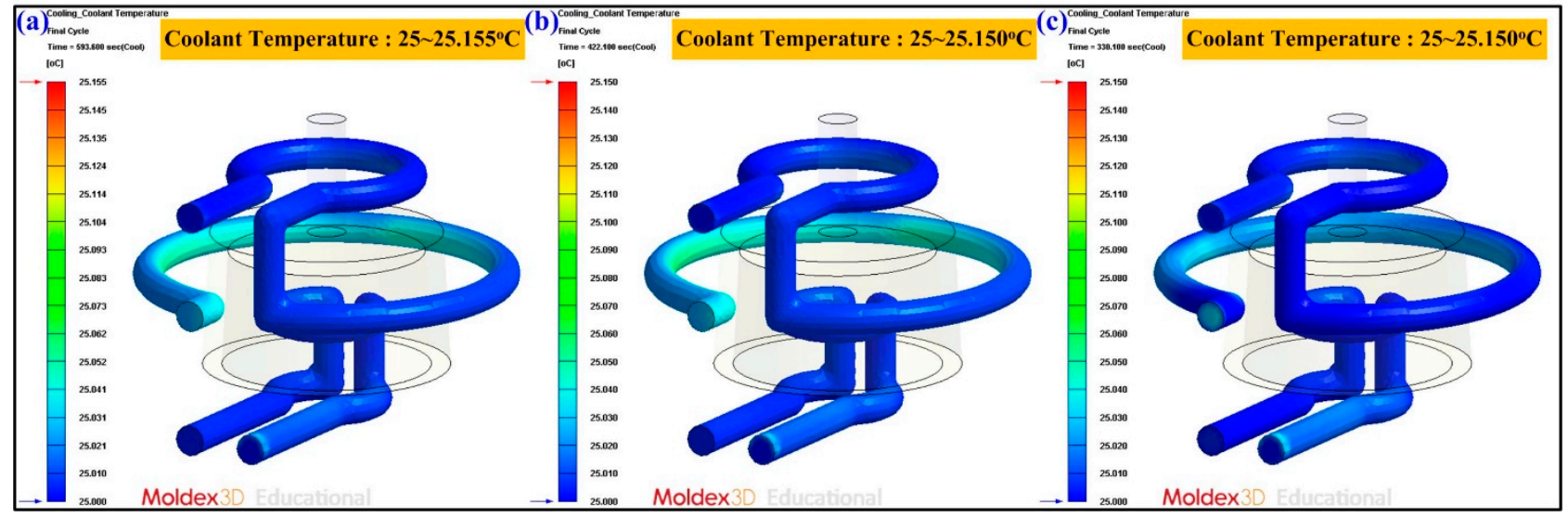

Figure 15. Numerical simulation results of the coolant temperature difference for (a) conventional SRM, (b) SRM with 60 wt.\% Al powder, and (c) SRM made with recipe 4.

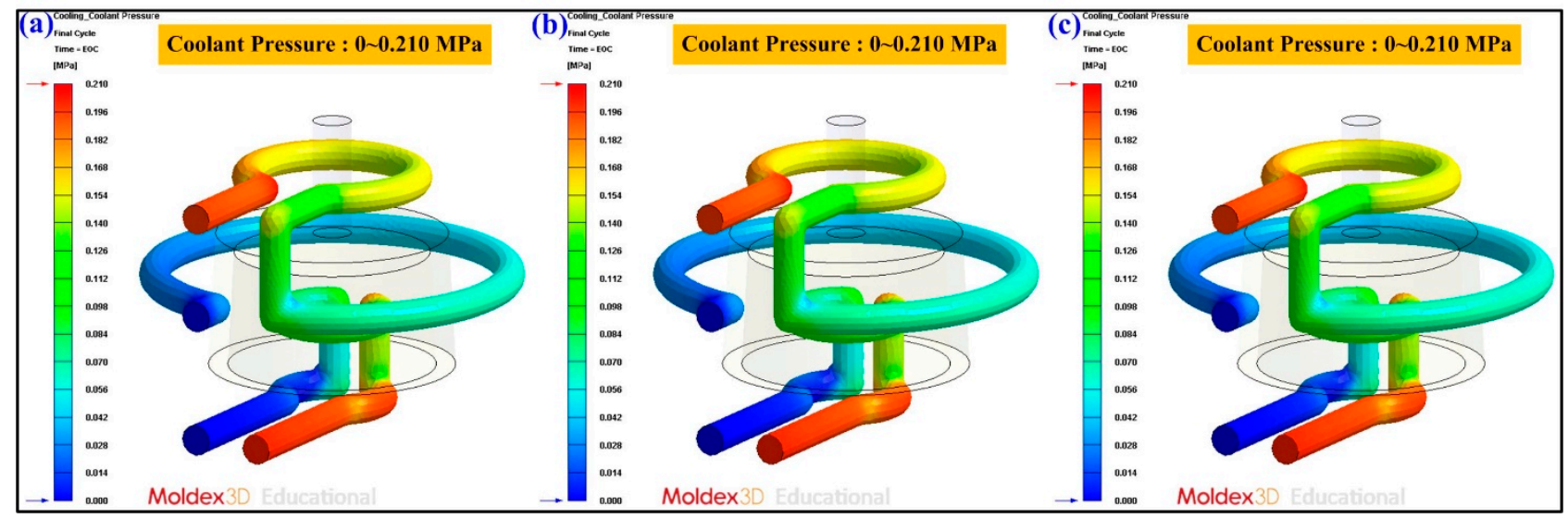

Figure 16. Numerical simulation results of the coolant pressure difference for (a) conventional SRM, (b) SRM with 60 wt.\% Al powder, and (c) SRM made with recipe 4.

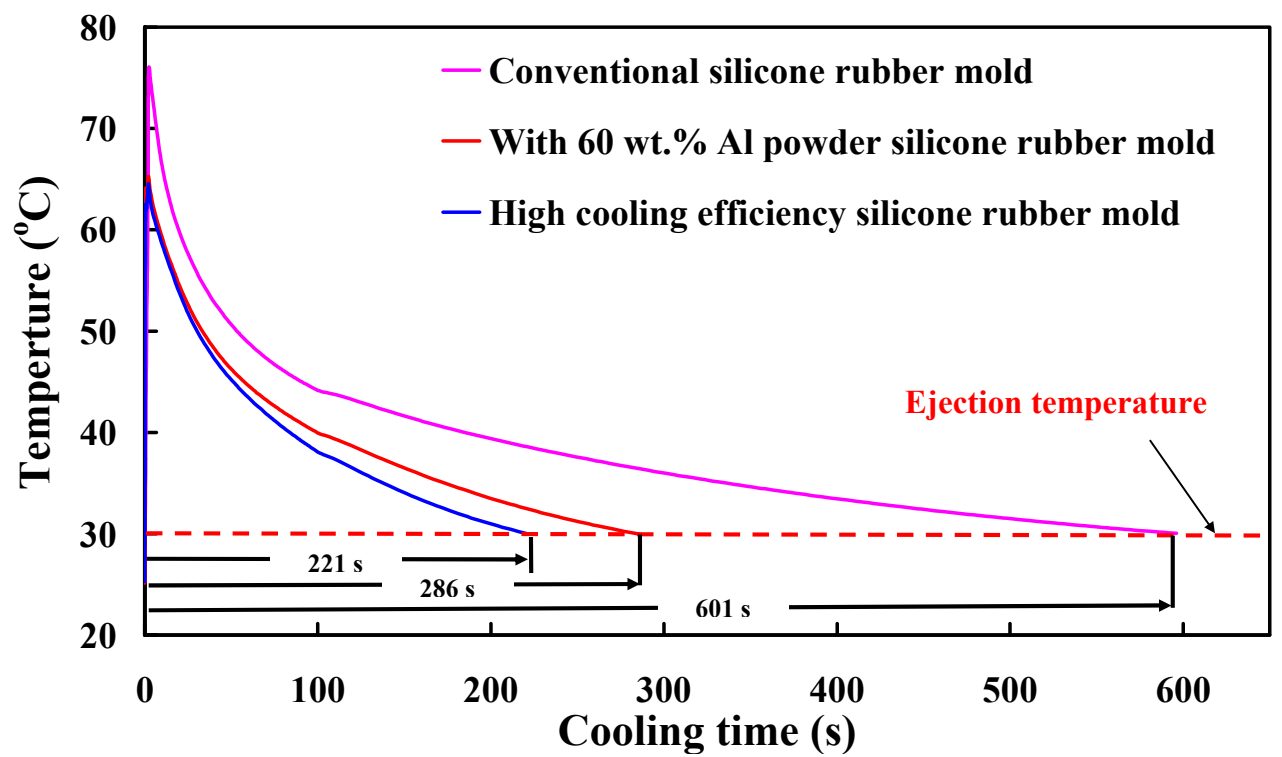

Figure 17. Numerical simulation results of the temperature of the molded wax pattern as a function of the cooling time. 


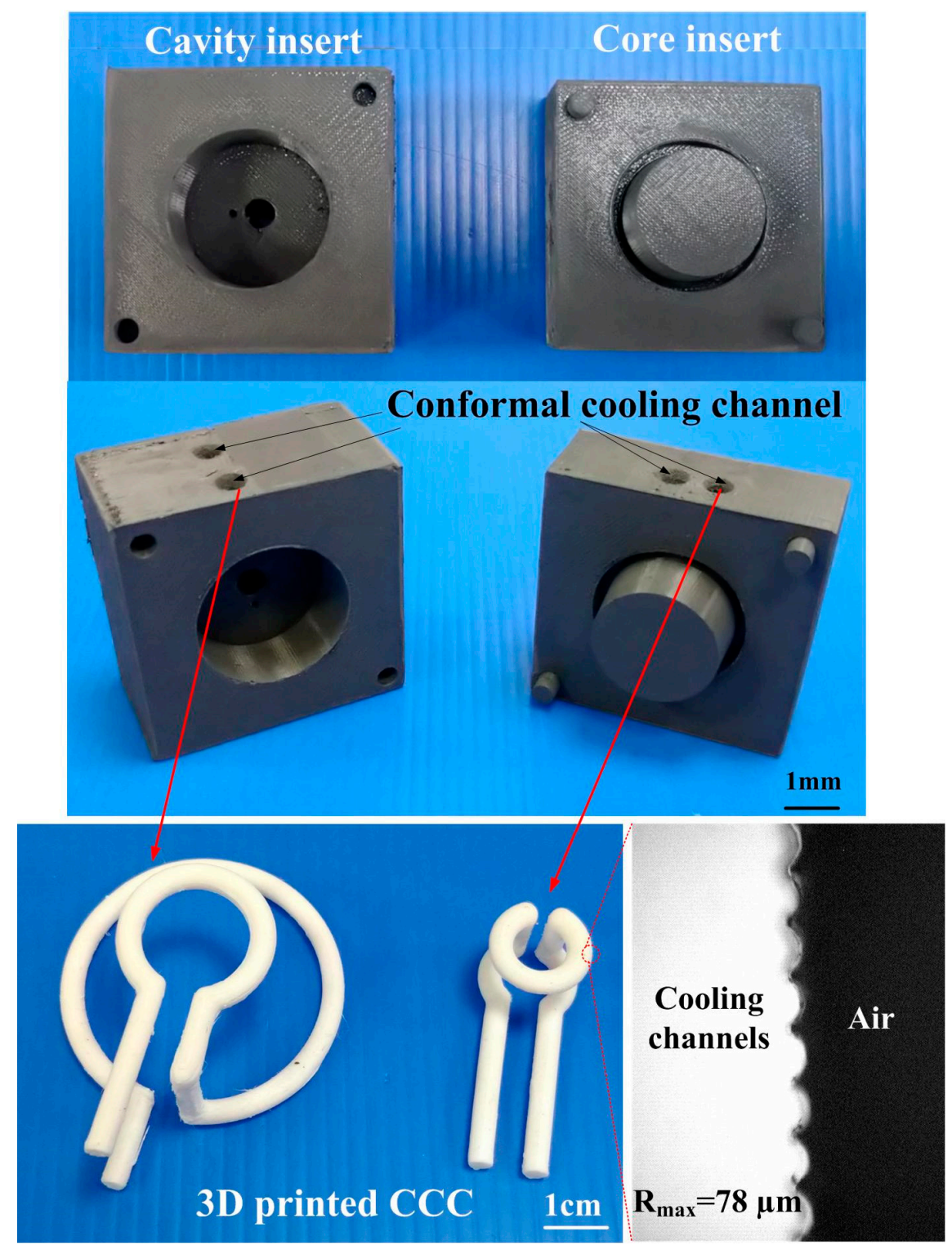

Figure 18. SRM made with recipe 4.

Figure 19 shows the temperature of the molded wax pattern as a function of actual cooling time. The cooling time of the injection molded product for conventional SRM, SRM with 60 wt.\% Al powder, and SRM made with optimal formulation are around $596 \mathrm{~s}, 198 \mathrm{~s}$, and $184 \mathrm{~s}$, respectively. The results revealed that SRM made with optimal formulation can save the cooling time of the injection molded product up to $69.1 \%$ compared to conventional SRM. In addition, SRM made with optimal formulation can save the cooling time of the injection molded product up to $66.8 \%$ compared to SRM with $60 \mathrm{wt}$. $\%$ Al. Two advantages were found from this result. First, it is interesting to note that the cooling time of the molded wax pattern fabricated by SRM made with the optimal formulation can be further saved by around $15.3 \%$ compared to that of the molded wax pattern fabricated by SRM with $80 \mathrm{wt}$.\% Fe powders [36]. Figure 20 shows the photo of a molded wax pattern. Second, the rust was not observed in the wall of the cooling channels of SRM after injection molding compared to SRM with 80 wt.\% Fe powders [36]. Figure 21 shows the comparison of the predicted and actual cooling time of injection molded products. Two phenomena were found. It was found that the cooling time obtained by the Moldex3D simulation software is greater than that obtained by the experiment. The relative error rates of the cooling time between the experiment and numerical simulation were about $1 \%, 45 \%$, and $20 \%$, 
respectively. This can be attributed to the difference between the experimental conditions and characteristic parameters such as molding material, mold materials, and responses of the injection machine used in the simulation software [51-53].
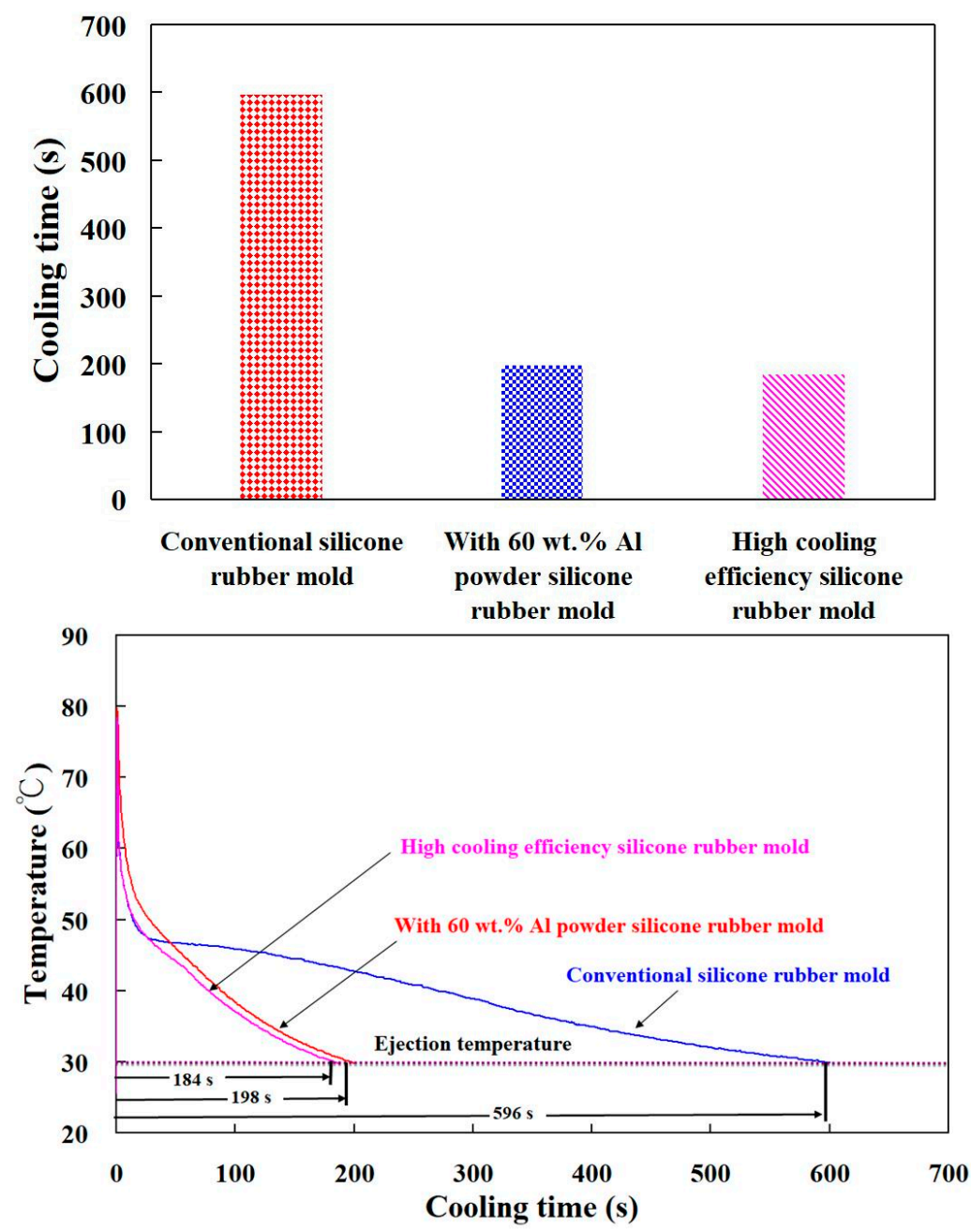

Figure 19. Temperature of the molded wax pattern as a function of actual cooling time.

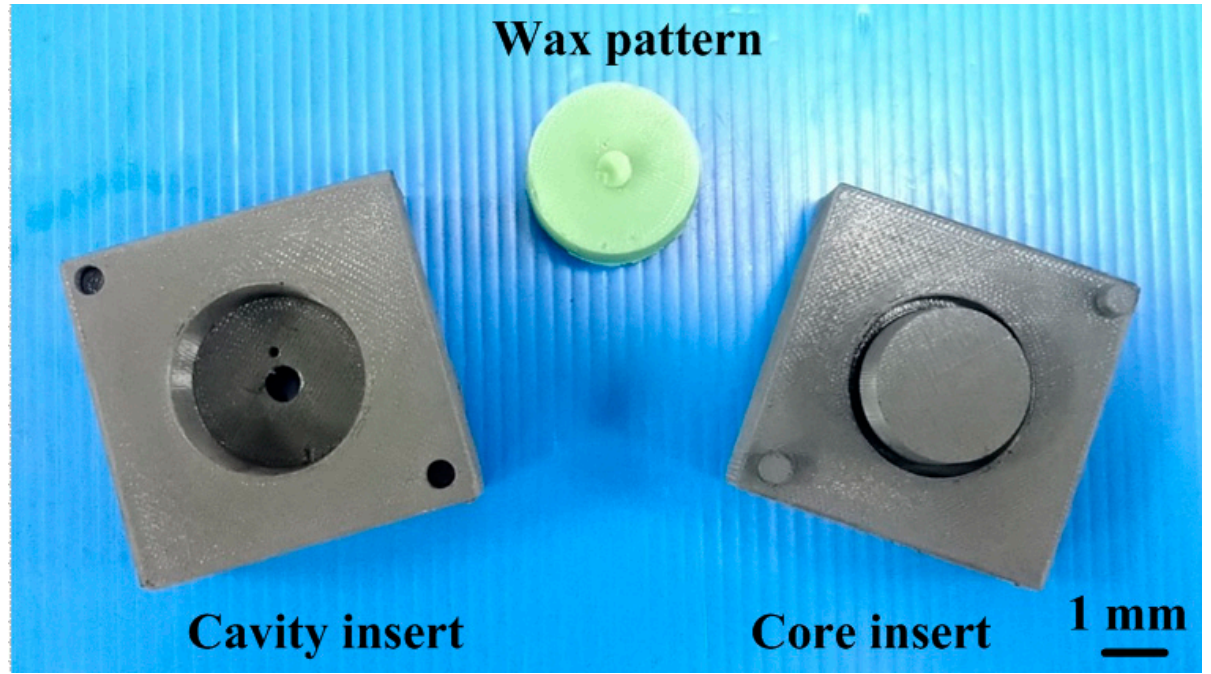

Figure 20. Photo of a molded wax pattern. 


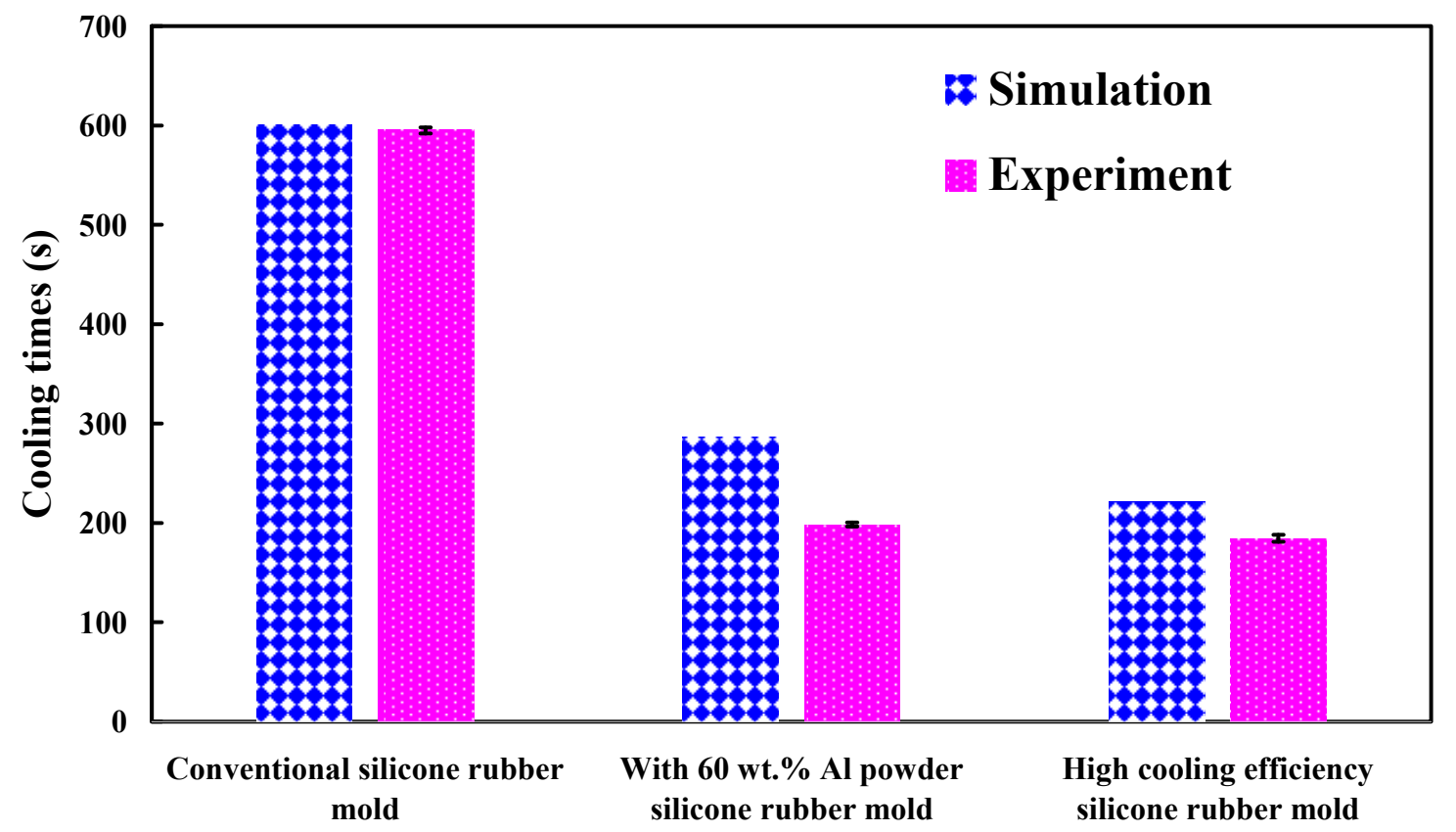

Figure 21. Comparison of the predicted and actual cooling time of injection molded products.

Cooling channel flow rate means the volumetric flow rate along the cooling channel. In general, higher flow rate will result in higher heat transfer. In practice, the cooling time plays an important role in the cycle time. Generally, the turbulent flow provides approximately three to five times as much heat transfer as laminar flow. To understand the effects of different coolant flow rates on the cooling time of the molded parts for high cooling efficiency SRM, four different coolant flow rates were carried out in this study. The Reynolds numbers for coolant flow rates of $95 \mathrm{cc} / \mathrm{s}, 115 \mathrm{cc} / \mathrm{s}, 125 \mathrm{cc} / \mathrm{s}$, and $135 \mathrm{cc} / \mathrm{s}$ are about $30,239,36,606,39,789$, and 42,972, respectively. Figure 22 shows the cooling time of the molded parts as a function of different coolant flow rates. The average cooling time of the molded parts for the coolant flow rates of $95 \mathrm{cc} / \mathrm{s}, 115 \mathrm{cc} / \mathrm{s}, 125 \mathrm{cc} / \mathrm{s}$, and $135 \mathrm{cc} / \mathrm{s}$ are $176 \mathrm{~s}, 179 \mathrm{~s}, 174 \mathrm{~s}$, and $176 \mathrm{~s}$, respectively. This means that changing the coolant flow rates has no significant effect on the cooling time of the molded parts because these four coolants have reached turbulent flow.

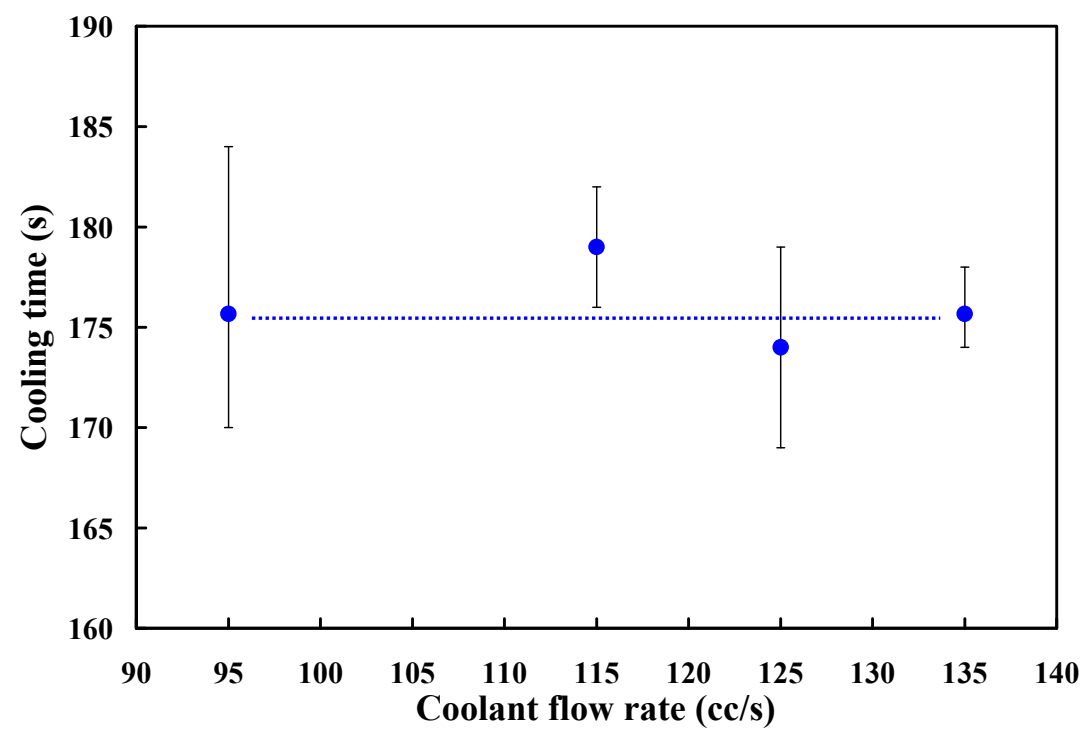

Figure 22. Cooling times of the molded parts as a function of different coolant flow rates. 
The coolant temperature is an important topic on the cooling efficiency for SRM with CCC. Coolant temperature reveals the temperature distribution inside the cooling channels. With the same flow strength, in general, lower coolant temperature can result in higher cooling efficiency. To understand the effects of different coolant temperatures on the cooling time of the molded parts for high cooling efficiency SRM, three different coolant temperatures were carried out in this study. Figure 23 shows the cooling time of the molded parts as a function of different coolant temperatures. The average cooling time of the molded parts for the coolant temperatures of $20^{\circ} \mathrm{C}, 25^{\circ} \mathrm{C}$, and $30^{\circ} \mathrm{C}$ are $131 \mathrm{~s}, 176 \mathrm{~s}$, and $374 \mathrm{~s}$, respectively. As can be seen, the cooling time of the molded parts decreases with decreasing coolant temperature. This means that changing the coolant temperatures has a significant effect on the cooling time of the molded parts.

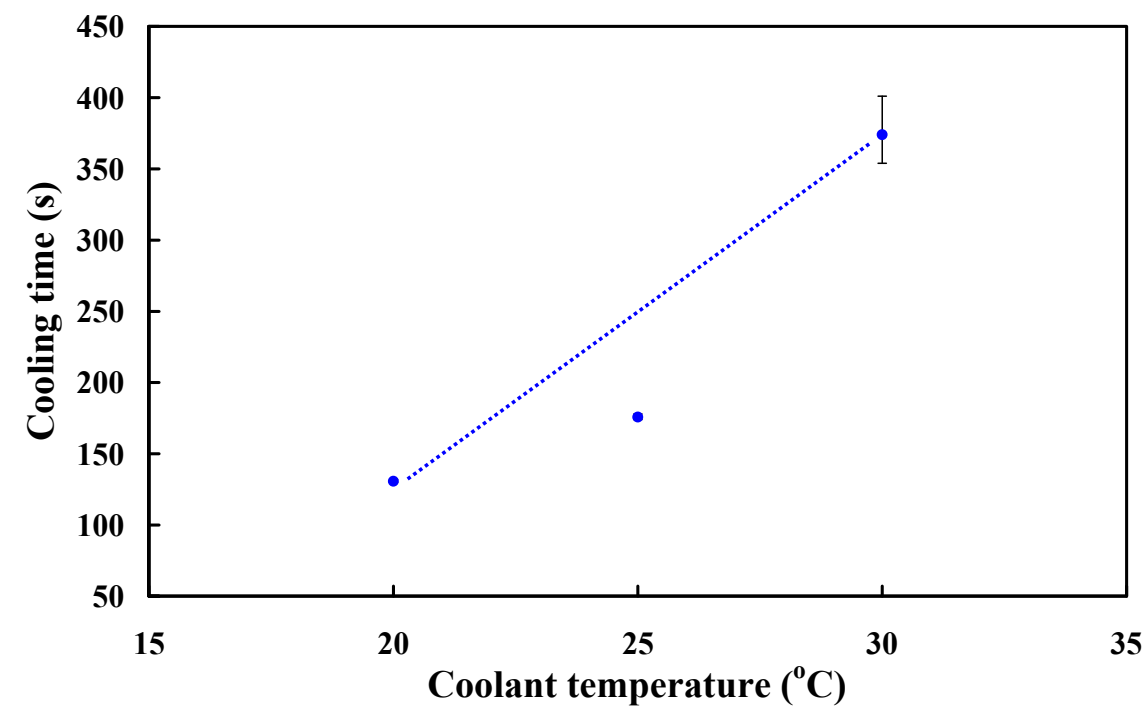

Figure 23. Cooling time of the molded parts as a function of different coolant temperatures.

In general, an intermediary mold which is complementary in shape to the core or cavity inserts was commonly used for fabricating RT. However, the production costs of a large intermediary mold are costly. To reduce the production costs, this study demonstrated an innovative method using polyurethane foam as backing material to make intermediary mold. Figure 24 shows an innovative method for fabricating an intermediary mold for large RT. The use of polyurethane foam (PUF) in the manufacturing process of an intermediary mold can reduce the usage amount of new liquid silicone rubber significantly. An intermediary mold was then fabricated by liquid silicone rubber (LSR) and PUF. The LSR was first used as surface material of the intermediary mold and the polyurethane foam was then used as the backing material. Finally, the backside of the intermediary mold was sealed with LSR. This innovative method has application potential for the RT industry because of the production cost reduction increases with increasing the sizes of the intermediary mold.

The price-performance ratio is defined as the ratio of the reduction in cooling time to the production cost. The production costs for conventional SRM and SRM made with recipe 4 are NTD 12.5 and NTD 19.3, respectively. This means that the price-performance ratio of this SRM made by the optimal recipe is around 55. It should be noted that the SRM made with recipe 4 seems to be a promising method to manufacture wax patterns for manufacturing customized metal components through investment casting technology [54-57]. However, adding fillers into the SRM changes the material composition, which brings other problems, including wasted material recycling and environmental friendliness are also important research issues. In addition, the CCCs inside the SRM were not optimized. Thus, further works are required to optimize the layout of the CCCs using the simulation software. The mechanical properties of SRM are inferior to that fabricated by aluminum 
(Al)-filled epoxy resins [58-61]. Therefore, the Al-filled epoxy resins can be used to make an injection molding tool with CCC for batch production of wax patterns. Unfortunately, the CCC in the injection molding tool was not optimized. Thus, optimization of CCC is also an important research issue using the Taguchi method [62-65]. Further improvements in the mechanical properties of the SRM with CCC by adding fillers or reinforcing additives, such as wollastonite, glass fibers, carbon fibers, glass sphere, molybdenum disulfide [66-69], zirconia [70-72], silica sand, or silicon nitride [73-75] into the SRB is also an important research issue. In addition, the internal surface of CCC has high surface roughness [76-78] and result in reduction in mold life due to stress concentration [79-82]. Thus, surface improvement of the CCC by abrasive flow machining [83], electrochemical polishing [84], chemical polishing [85], laser polishing [86], ultrasonic cavitation abrasive finishing [87], or abrasive blasting [88] is also an important research topic. These issues are currently being investigated and the results will be presented in a later study.

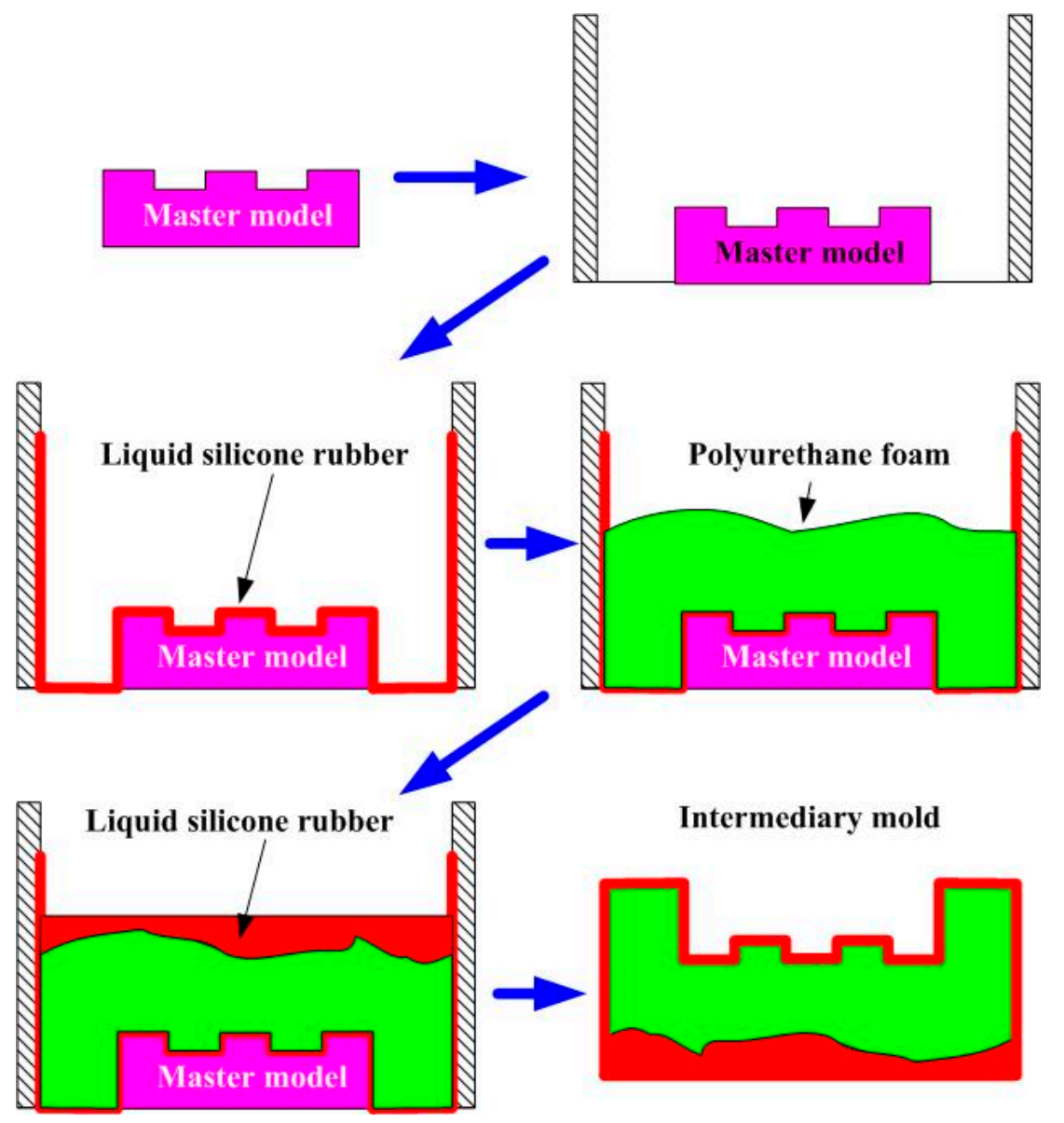

Figure 24. An innovative method for fabricating an intermediary mold for large rapid tooling (RT) with.

\section{Conclusions}

The productivity was influenced by the cooling time significantly in the wax injection molding process since the cooling time accounts for approximately two thirds of the cycle time. Thus, improving the cooling efficiency of the SRM is an important research issue. The objective of this study is to develop a recipe for manufacturing low-cost SRM with high cooling performance and resistance to rust. The remarkable findings of this study can be used for the fabrication of SRM for trial production of wax patterns in the investment casting industry. Based on the results obtained in this study, the following conclusions can be drawn: 
1. Improving cooling performance of injection molding tool with CCC by adding hybrid fillers has been demonstrated. An optimal recipe comprising $52.6 \mathrm{wt} . \% \mathrm{Al}$ powder, $5.3 \mathrm{wt} . \% \mathrm{G}$ powder, and $42.1 \mathrm{wt}$.\% liquid silicon rubber can be used to make SRM with excellent cooling efficiency. The price-performance ratio of this SRM made by the proposed recipe is around 55 .

2. The thermal conductivity of the SRM made by the proposed recipe can be increased by up to $77.6 \%$ compared with conventional SRM. In addition, the actual cooling time of the injection molded product can be shortened up to $69.1 \%$ compared with the conventional SRM.

3. For the SRM made by the proposed recipe, the relative error rate of the cooling time between the experiment and numerical simulation was approximately $20 \%$.

4. Changing the coolant temperatures has a significant effect on the cooling time of the molded parts. However, changing the coolant flow rates has no significant effect on the cooling time of the molded parts.

Author Contributions: C.-C.K.: wrote the paper/conceived and designed the analysis/performed the analysis/conceptualization. W.-H.C.: collected the data/contributed data or analysis tools. All authors have read and agreed to the published version of the manuscript.

Funding: This study received financial support by the Ministry of Science and Technology of Taiwan under contract nos. MOST 109-2637-E-131-004 and MOST 107-2221-E-131-018.

Institutional Review Board Statement: Not applicable.

Informed Consent Statement: Not applicable.

Data Availability Statement: The data presented in this study are available on request from the corresponding author.

Conflicts of Interest: The authors declare no conflict of interest.

\section{References}

1. Simha Martynková, G.; Slíva, A.; Kratošová, G.; Čech Barabaszová, K.; Študentová, S.; Klusák, J.; Brožová, S.; Dokoupil, T.; Holešová, S. Polyamide 12 Materials Study of Morpho-Structural Changes during Laser Sintering of 3D Printing. Polymers 2021, 13, 810. [CrossRef] [PubMed]

2. Saleh Alghamdi, S.; John, S.; Roy Choudhury, N.; Dutta, N.K. Additive Manufacturing of Polymer Materials: Progress, Promise and Challenges. Polymers 2021, 13, 753. [CrossRef]

3. Mantelli, A.; Romani, A.; Suriano, R.; Diani, M.; Colledani, M.; Sarlin, E.; Turri, S.; Levi, M. UV-Assisted 3D Printing of Polymer Composites from Thermally and Mechanically Recycled Carbon Fibers. Polymers 2021, 13, 726. [CrossRef]

4. Park, J.; Zobaer, T.; Sutradhar, A. A Two-Scale Multi-Resolution Topologically Optimized Multi-Material Design of 3D Printed Craniofacial Bone Implants. Micromachines 2021, 12, 101. [CrossRef] [PubMed]

5. Kalami, H.; Urbanic, R.J. Design and fabrication of a low-volume, high-temperature injection mould leveraging a 'rapid tooling' approach. Int. J. Adv. Manuf. Technol. 2019, 105, 3797-3813. [CrossRef]

6. Kuo, C.-C.; Nguyen, T.-D.; Zhu, Y.-J.; Lin, S.-X. Rapid Development of an Injection Mold with High Cooling Performance Using Molding Simulation and Rapid Tooling Technology. Micromachines 2021, 12, 311. [CrossRef]

7. Wu, H.; Lu, B.; Guo, C.; Wei, R. Structural analysis on the arc spraying rapid tooling for sheet forming. Int. J. Adv. Manuf. Technol. 2015, 77, 2277-2287. [CrossRef]

8. Meng, F.; Zhang, H.; Wang, G. Experiment research on green machining of clay prototype for plasma spray tooling. Int. J. Adv. Manuf. Technol. 2014, 70, 1415-1419. [CrossRef]

9. Wang, D.; Dong, A.; Zhu, G.; Shu, D.; Sun, J.; Li, F.; Sun, B. Rapid casting of complex impeller based on 3D printing wax pattern and simulation optimization. Int. J. Adv. Manuf. Technol. 2019, 100, 2629-2635. [CrossRef]

10. Kuo, C.C.; Chen, W.H.; Liu, X.Z.; Liao, Y.L.; Chen, W.J.; Huang, B.Y.; Tsai, R.L. Development of a low-cost wax injection mold with high cooling efficiency. Int. J. Adv. Manuf. Technol. 2017, 93, 2081-2088. [CrossRef]

11. Kuo, C.C.; Xu, W.C. Effects of different cooling channels on the cooling efficiency in the wax injection molding process. Int. J. Adv. Manuf. Technol. 2018, 98, 887-895. [CrossRef]

12. Yuan, B.; Wang, Z.; Fang, W.; Li, J. Rheological experimental properties and numerical modeling of a pressure-transmitting silicone rubber used in sheet metal flexible-die forming. Int. J. Adv. Manuf. Technol. 2018, 95, 1697-1714. [CrossRef]

13. Wu, J.; Zhang, C.; Su, B.; Dong, J.; Wang, Y.; Gond, B.K. New method for studying the macro-micro contact properties between smooth metal and silicone rubber. Int. J. Adv. Manuf. Technol. 2018, 96, 1761-1767. [CrossRef] 
14. He, Z.; Lu, B.; Hong, J.; Wang, Y.; Tang, Y. A novel arc-spraying robot for rapid tooling. Int. J. Adv. Manuf. Technol. 2017, 31, 1012-1020. [CrossRef]

15. Rajaguru, J.; Duke, M.; Au, C. Development of rapid tooling by rapid prototyping technology and electroless nickel plating for low-volume production of plastic parts. Int. J. Adv. Manuf. Technol. 2015, 78, 31-40. [CrossRef]

16. Issa, M.; Petkovic, D.; Pavlovic, N.D.; Zentner, L. Sensor elements made of conductive silicone rubber for passively compliant gripper. Int. J. Adv. Manuf. Technol. 2013, 69, 1527-1536. [CrossRef]

17. Ou, H.; Sahli, M.; Barrière, T.; Gelin, J.C. Multiphysics modelling and experimental investigations of the filling and curing phases of bi-injection moulding of thermoplastic polymer/liquid silicone rubbers. Int. J. Adv. Manuf. Technol. 2017, 92, 3871-3882. [CrossRef]

18. Ou, H.; Sahli, M.; Barriere, T.; Gelin, J.C. Experimental characterisation and modelling of rheokinetic properties of different silicone elastomers. Int. J. Adv. Manuf. Technol. 2017, 92, 4199-4211. [CrossRef]

19. Yang, G.; Makarova, O.V.; Amstutz, P.; Tang, C.M. Rapid replication of powder composite high-aspect-ratio microstructures using silicone rubber micromolds. Microsyst. Technol. 2008, 14, 1663-1667. [CrossRef]

20. Thian, S.C.H.; Fuh, J.Y.H.; Wong, Y.S.; Loh, H.T.; Gian, P.W.; Tang, Y. Fabrication of microfluidic channel utilizing silicone rubber with vacuum casting. Microsyst. Technol. 2008, 14, 1125-1135. [CrossRef]

21. Glocker, D.; Wiseman, R. A new method for the batch production of micro-Fresnel zone plates. J. Vac. Sci. Technol. 1982, 20, 1098-1100. [CrossRef]

22. Christian, P.; Jones, I.A.; Rudd, C.D.; Campbell, R.I.; Corden, T.J. Monomer transfer moulding and rapid prototyping methods for fibre reinforced thermoplastics for medical applications. Compos. Part. A Appl. Sci. Manuf. 2001, 32, 969-976. [CrossRef]

23. Ching, L.S.; Kai, C.C.; Meng, C.S. A novel technique for fabricating facial prosthetic model. Medicine and Biology Society, Proceedings of the 20th Annual International. Conf. IEEE Eng. Med. Biol. Soc. 1998, 20, 2746-2749.

24. Maji, P.K.; Banerjee, P.S.; Sinha, A. Application of rapid prototyping and rapid tooling for development of patient-specific craniofacial implant: An investigative study. Int. J. Adv. Manuf. Technol. 2008, 36, 510-515. [CrossRef]

25. Kozior, T.; Bochnia, J.; Zmarzły, P.; Gogolewski, D.; Mathia, T.G. Waviness of Freeform Surface Characterizations from Austenitic Stainless Steel (316L) Manufactured by 3D Printing-Selective Laser Melting (SLM) Technology. Materials 2020, 13 , 4372.

26. Kozior, T.; Kundera, C. Surface texture of models manufactured by FDM technology. In Proceedings of the AIP Conference Proceedings; AIP Publishing LLC: Melville, NY, USA, 2018; Volume 2017, p. 20011. [CrossRef]

27. Reggiani, B.; Todaro, I. Investigation on the design of a novel selective laser melted insert for extrusion dies with conformal cooling channels. Int. J. Adv. Manuf. Technol. 2019, 104, 815-830. [CrossRef]

28. Kanbur, B.B.; Suping, S.; Duan, F. Design and optimization of conformal cooling channels for injection molding: A review. Int. J. Adv. Manuf. Technol. 2020, 106, 3253-3271. [CrossRef]

29. Vojnova, E. The Benefits of a Conforming Cooling Systems the Molds in Injection Moulding Process. Procedia Eng. 2016, 149, 535-543. [CrossRef]

30. Kitayama, S.; Miyakawa, H.; Takano, M.; Aiba, S. Multi-objective optimization of injection molding process parameters for short cycle time and warpage reduction using conformal cooling channel. Int. J. Adv. Manuf. Technol. 2017, 88, 1735-1744. [CrossRef]

31. Holker, R.; Tekkaya, A.E. Advancements in the manufacturing of dies for hot aluminum extrusion with conformal cooling channels. Int. J. Adv. Manuf. Technol. 2016, 83, 1209-1220. [CrossRef]

32. Lim, W.S.; Choi, H.S.; Ahn, S.Y.; Kim, B.M. Cooling channel design of hot stamping tools for uniform high-strength components in hot stamping process. Int. J. Adv. Manuf. Technol. 2014, 70, 1189-1203. [CrossRef]

33. Wang, X.; Li, Z.; Gu, J.; Ruan, S.; Shen, C.; Wang, X. Reducing service stress of the injection-molded polycarbonate window by optimizing mold construction and product structure. Int. J. Adv. Manuf. Technol. 2016, 86, 1691-1704. [CrossRef]

34. Brooks, H.; Brigden, K. Design of conformal cooling layers with self-supporting lattices for additively manufactured tooling. Addit. Manuf. 2016, 11, 16-22. [CrossRef]

35. Hsu, F.H.; Wang, K.; Huang, C.T.; Chang, R.Y. Investigation on conformal cooling system design in injection molding. Adv. Prod. Eng. Manag. 2013, 8, 107-115. [CrossRef]

36. Kuo, C.-C.; Chen, W.-H.; Lin, Y.-X.; Gao, Q.; Gian, S.-J.; Xiao, C.-X. Effects of different fillers on the silicone rubber mold with conformal cooling channels. Int. J. Adv. Manuf. Technol. 2020, 108, 1509-1525. [CrossRef]

37. Ujah, C.O.; Popoola, A.P.I.; Popoola, O.M.; Aigbodion, V.S. Influence of CNTs addition on the mechanical, microstructural, and corrosion properties of $\mathrm{Al}$ alloy using spark plasma sintering technique. Int. J. Adv. Manuf. Technol. 2020, 106, 2961-2969. [CrossRef]

38. Hakem, M.; Lebaili, S.; Mathieu, S.; Miroud, D.; Lebaili, A.; Cheniti, B. Effect of microstructure and precipitation phenomena on the mechanical behavior of AA6061-T6 aluminum alloy weld. Int. J. Adv. Manuf. Technol. 2019, 102, 2907-2918. [CrossRef]

39. ChiaroniZ, A.B.; Silveira, C. Experimental and numerical evaluation of the temperature profile of a modular extrusion head applied to an experimental 3D printer. Int. J. Adv. Manuf. Technol. 2019, 103, 4385-4398. [CrossRef]

40. Kitayama, S.; Yokoyama, M.; Takano, M.; Aiba, S. Multi-objective optimization of variable packing pressure profile and process parameters in plastic injection molding for minimizing warpage and cycle time. Int. J. Adv. Manuf. Technol. 2017, 92, 3991-3999. [CrossRef]

41. Ryu, Y.; Sohn, J.S.; Yun, C.-S.; Cha, S.W. Shrinkage and Warpage Minimization of Glass-Fiber-Reinforced Polyamide 6 Parts by Microcellular Foam Injection Molding. Polymers 2020, 12, 889. [CrossRef] 
42. Yasin, S.B.M.; Mohd, N.F.; Mahmud, J.; Whashilah, N.S.; Razak, Z. A reduction of protector cover warpage via topology optimization. Int. J. Adv. Manuf. Technol. 2018, 98, 2531-2537. [CrossRef]

43. Song, Z.; Liu, S.; Wang, X.; Hu, Z. Optimization and prediction of volume shrinkage and warpage of injection-molded thin-walled parts based on neural network. Int. J. Adv. Manuf. Technol. 2020, 109, 755-769. [CrossRef]

44. Zhang, C.; Shahriari, D.; Loucif, A.; Melkonyan, H.; Jahazi, M. Influence of thermomechanical shrinkage on macrosegregation during solidification of a large-sized high-strength steel ingot. Int. J. Adv. Manuf. Technol. 2018, 99, 3035-3048. [CrossRef]

45. Krebelj, K.; Mole, N.; Štok, B. Three-dimensional modeling of the stress evolution in injection molded parts based on a known melt pressure field. Int. J. Adv. Manuf. Technol. 2017, 90, 2363-2376. [CrossRef]

46. Singh, R.; Madan, J. A computer-aided system for multi-gate gating-system design for die-casting dies. Int. J. Adv. Manuf. Technol. 2019, 101, 1793-1806. [CrossRef]

47. Li, F.; Wang, D.; Jiang, Y.; Yang, L.; Zhao, Y.; Zhang, X. Effect of centrifugal casting process on mold filling and grain structure of K418B turbine guide. Int. J. Adv. Manuf. Technol. 2019, 104, 3065-3072. [CrossRef]

48. Feng, Q.; Liu, L.; Zhou, X. Automated multi-objective optimization for thin-walled plastic products using Taguchi, ANOVA, and hybrid ANN-MOGA. Int. J. Adv. Manuf. Technol. 2020, 106, 559-575. [CrossRef]

49. Gao, H.; Zhang, Y.; Fu, Y.; Mao, T.; Zhou, H.; Li, D. Process parameters optimization using a novel classification model for plastic injection molding. Int. J. Adv. Manuf. Technol. 2018, 94, 357-370. [CrossRef]

50. Izadi, O.; Silani, M.; Mosaddegh, P.; Farzin, M. Warpage and bending behavior of polymer-metal hybrids: Experimental and numerical simulations. Int. J. Adv. Manuf. Technol. 2018, 98, 873-885. [CrossRef]

51. Park, H.; Rhee, B. Effects of the viscosity and thermal property of fluids on the residual wall thickness and concentricity of the hollow products in fluid-assisted injection molding. Int. J. Adv. Manuf. Technol. 2016, 86, 3255-3265. [CrossRef]

52. Lu, L.; Han, J.; Fan, C.; Xia, L. A predictive feedrate schedule method for sculpture surface machining and corresponding B-spline-based irredundant PVT commands generating method. Int. J. Adv. Manuf. Technol. 2018, 98, 1763-1782. [CrossRef]

53. Lan, X.; Li, C.; Yang, L.; Xue, C. Deformation analysis and improvement method of the Ni-P mold core in the injection molding process. Int. J. Adv. Manuf. Technol. 2018, 99, 2659-2668. [CrossRef]

54. Wang, D.; Sun, J.; Dong, A.; Shu, D.; Zhu, G.; Sun, B. An optimization method of gating system for impeller by RSM and simulation in investment casting. Int. J. Adv. Manuf. Technol. 2018, 98, 3105-3114. [CrossRef]

55. Wang, D.; Dong, A.; Zhu, G.; Shu, D.; Li, F. The propagation and accumulation of dimensional shrinkage for ring-to-ring structure in investment casting. Int. J. Adv. Manuf. Technol. 2018, 96, 623-629. [CrossRef]

56. Zhang, S.; Xu, Z.G.; Wang, Z. Numerical modeling and simulation of water cooling-controlled solidification for aluminum alloy investment casting. Int. J. Adv. Manuf. Technol. 2017, 91, 763-770. [CrossRef]

57. Li, H.; Chen, J.; Chandrashekhara, K.; Xu, M.; Lekakh, S.N.; Richards, V.L. Characterization and modeling of anisotropic SL pattern during investment casting process. Int. J. Adv. Manuf. Technol. 2015, 80, 1933-1943. [CrossRef]

58. Kuo, C.; Lyu, S. A cost-effective approach using recycled materials to fabricate micro-hot embossing dies for microfabrication. Int J. Adv. Manuf. Technol. 2018, 94, 4365-4371. [CrossRef]

59. Kuo, C.; Chen, W.; Xu, W. A cost-effective approach for rapid manufacturing wax injection molds with complex geometrical shapes of cooling channels. Int. J. Adv. Manuf. Technol. 2017, 91, 1689-1695. [CrossRef]

60. Kuo, C.; Lin, J. A cost-effective method for rapid manufacturing polymer rapid tools used for liquid silicone rubber injection molding. Int. J. Adv. Manuf. Technol. 2019, 104, 1159-1170. [CrossRef]

61. Kuo, C.; Wang, Y. Optimization of plasma surface modification parameter for fabricating a hot embossing mold with high surface finish. Int. J. Adv. Manuf. Technol. 2017, 91, 3363-3369. [CrossRef]

62. Zhou, M.; Kong, L.; Xie, L.; Fu, T.; Jiang, G.; Feng, Q. Design and optimization of non-circular mortar nozzles using finite volume method and Taguchi method. Int. J. Adv. Manuf. Technol. 2017, 90, 3543-3553. [CrossRef]

63. Chen, W.C.; Nguyen, M.H.; Chiu, W.H.; Chen, T.N.; Tai, P.H. Optimization of the plastic injection molding process using the Taguchi method, RSM, and hybrid GA-PSO. Int. J. Adv. Manuf. Technol. 2016, 83, 1873-1886. [CrossRef]

64. Adnan, M.F.; AbdullahE, A.B.; Samad, Z. Springback behavior of AA6061 with non-uniform thickness section using Taguchi Method. Int. J. Adv. Manuf. Technol. 2017, 89, 2041-2052. [CrossRef]

65. Lin, C.-M.; Hung, Y.-T.; Tan, C.-M. Hybrid Taguchi-Gray Relation Analysis Method for Design of Metal Powder Injection-Molded Artificial Knee Joints with Optimal Powder Concentration and Volume Shrinkage. Polymers 2021, 13, 865. [CrossRef] [PubMed]

66. Gong, G.; Chen, J.C.; Guo, G. Enhancing tensile strength of injection molded fiber reinforced composites using the Taguchi-based six sigma approach. Int. J. Adv. Manuf. Technol. 2017, 91, 3385-3393. [CrossRef]

67. Darshan, C.; Jain, S.; Dogra, M.; Gupta, M.K.; Mia, M.; Haque, R. Influence of dry and solid lubricant-assisted MQL cooling conditions on the machinability of Inconel 718 alloy with textured tool. Int. J. Adv. Manuf. Technol. 2019, 105, 1835-1849. [CrossRef]

68. Jia, D.; Li, C.; Zhang, Y.; Zhang, D.; Zhang, X. Experimental research on the influence of the jet parameters of minimum quantity lubrication on the lubricating property of Ni-based alloy grinding. Int. J. Adv. Manuf. Technol. 2016, 82, 617-630. [CrossRef]

69. Wojtewicz, M.; Nadolny, K.; Kapłonek, W.; Rokosz, K.; Matýsek, D.; Ungureanu, M. Experimental studies using minimum quantity cooling (MQC) with molybdenum disulfide and graphite-based microfluids in grinding of Inconel alloy 718. Int. J. Adv. Manuf. Technol. 2019, 101, 637-661. [CrossRef] 
70. Abdo, B.M.A.; El-Tamimi, A.M.; Anwar, S.; Umer, U.; Alahmari, A.M.; Ghaleb, M.A. Experimental investigation and multiobjective optimization of Nd:YAG laser micro-channeling process of zirconia dental ceramic. Int. J. Adv. Manuf. Technol. 2018, 98, 2213-2230. [CrossRef]

71. Yang, M.; Li, C.; Zhang, Y.; Jia, D.; Li, R.; Hou, Y.; Cao, H. Effect of friction coefficient on chip thickness models in ductile-regime grinding of zirconia ceramics. Int. J. Adv. Manuf. Technol. 2019, 102, 2617-2632. [CrossRef]

72. Xu, S.; Yao, Z.; Cai, H.; Wang, H. An experimental investigation of grinding force and energy in laser thermal shock-assisted grinding of zirconia ceramics. Int. J. Adv. Manuf. Technol. 2017, 91, 3299-3306. [CrossRef]

73. Kim, T.W.; Lee, C.M. A study on the development of milling process for silicon nitride using ball end-mill tools by laser-assisted machining. Int. J. Adv. Manuf. Technol. 2015, 77, 1205-1211. [CrossRef]

74. Azarhoushang, B.; Soltani, B.; Zahedi, A. Laser-assisted grinding of silicon nitride by picosecond laser. Int. J. Adv. Manuf. Technol. 2017, 93, 2517-2529. [CrossRef]

75. Laouissi, A.; Yallese, M.A.; Belbah, A.; Belhadi, S.; Haddad, A. Investigation, modeling, and optimization of cutting parameters in turning of gray cast iron using coated and uncoated silicon nitride ceramic tools. Based on ANN, RSM, and GA optimization. Int. J. Adv. Manuf. Technol. 2019, 101, 523-548. [CrossRef]

76. Wei, H.; Hussain, G.; Iqbal, A.; Zhang, Z.P. Surface roughness as the function of friction indicator and an important parameterscombination having controlling influence on the roughness: Recent results in incremental forming. Int. J. Adv. Manuf. Technol. 2019, 101, 2533-2545. [CrossRef]

77. Saad, M.S.; Nor, A.M.; Baharudin, M.E.; Zakaria, M.Z.; Aiman, A. Optimization of surface roughness in FDM 3D printer using response surface methodology, particle swarm optimization, and symbiotic organism search algorithms. Int. J. Adv. Manuf. Technol. 2019, 105, 5121-5137. [CrossRef]

78. Su, H.; Yang, C.; Gao, S.; Fu, Y.; Ding, W. A predictive model on surface roughness during internal traverse grinding of small holes. Int. J. Adv. Manuf. Technol. 2019, 103, 2069-2077. [CrossRef]

79. Makki, M.M.; Ahmed, B.; Chokri, B. Reliability prediction of the stress concentration factor using response surface method. Int. J. Adv. Manuf. Technol. 2018, 94, 817-826. [CrossRef]

80. El Moumen, A.; Tarfaoui, M.; Lafdi, K. Modelling of the temperature and residual stress fields during 3D printing of polymer composites. Int. J. Adv. Manuf. Technol. 2019, 104, 1661-1676. [CrossRef]

81. Ali, H.; Ghadbeigi, H.; Hosseinzadeh, F.; Oliveira, J.; Mumtaz, K. Effect of pre-emptive in situ parameter modification on residual stress distributions within selective laser-melted Ti6Al4V components. Int. J. Adv. Manuf. Technol. 2019, 103, 4467-4479. [CrossRef]

82. Laamouri, A.; Ghanem, F.; Braham, C.; Sidhom, H. Influences of up-milling and down-milling on surface integrity and fatigue strength of X160CrMoV12 steel. Int. J. Adv. Manuf. Technol. 2019, 105, 1209-1228. [CrossRef]

83. Munhoz, M.R.; Dias, L.G.; Breganon, R.; Ribeiro, F.S.F.; Gonçalves, J.F.D.S.; Hashimoto, E.M.; Júnior, C.E.D.S. Analysis of the surface roughness obtained by the abrasive flow machining process using an abrasive paste with oiticica oil. Int. J. Adv. Manuf. Technol. 2020, 106, 5061-5070. [CrossRef]

84. Dong, G.; Marleau-Finley, J.; Zhao, Y.F. Investigation of electrochemical post-processing procedure for Ti-6Al-4V lattice structure manufactured by direct metal laser sintering (DMLS). Int. J. Adv. Manuf. Technol. 2019, 104, 3401-3417. [CrossRef]

85. Tyagi, P.; Goulet, T.; Riso, C.; Garcia-Moreno, F. Reducing surface roughness by chemical polishing of additively manufactured 3D printed 316 stainless steel components. Int. J. Adv. Manuf. Technol. 2019, 100, 2895-2900. [CrossRef]

86. Yung, K.C.; Zhang, S.S.; Duan, L.; Choy, H.S.; Cai, Z.X. Laser polishing of additive manufactured tool steel components using pulsed or continuous-wave lasers. Int. J. Adv. Manuf. Technol. 2019, 105, 425-440. [CrossRef]

87. Nagalingam, A.P.; Yeo, S.H. Effects of ambient pressure and fluid temperature in ultrasonic cavitation machining. Int. J. Adv. Manuf. Technol. 2018, 98, 2883-2894. [CrossRef]

88. Jin, S.Y.; Pramanik, A.; Basak, A.K.; Prakash, C.; Shankar, S.; Debnath, S. Burr formation and its treatments-A review. Int. J. Adv. Manuf. Technol. 2020, 107, 2189-2210. [CrossRef] 